\title{
Time-Dependent Island Rule and Its Application to the Time-Varying North Hawaiian Ridge Current**
}

\author{
ERIC FiRing, Bo QiU, AND WeIFEng MiaO \\ Department of Oceanography, University of Hawaii at Manoa, Honolulu, Hawaii
}

(Manuscript received 30 June 1997, in final form 6 January 1999)

\begin{abstract}
Since November 1988, repeated shipboard ADCP transects have been made across the North Hawaiian Ridge Current (NHRC) north of Oahu. Prominent aspects of the NHRC transport time series include 1) a shift in late 1991 from a relatively strong and steady state to a weaker and more variable state and 2) the absence of an annual cycle, despite the annual cycle in the wind stress.

A simple conceptual framework for understanding NHRC variability is provided by our extension of Godfrey's island rule to upper-layer flow in the baroclinic time-dependent case. The interior ocean flow east of the islands is viewed as the sum of Ekman transport, geostrophic adjustment to Ekman pumping, and long Rossby waves. The net interior flow normal to the offshore edge of the NHRC is carried around the island barrier, with the split between northward and southward flow governed by a simple vorticity constraint involving only the inflow and outflow from the interior and the wind circulation around the island. The latter is of minor importance to the Hawaiian Islands. The time-dependent island rule calculation does not reproduce the observed time series, but it approximates the observed magnitude and character of variability. The result is sensitive to the choice of wind product.

To improve the simulation and to investigate the importance of processes missing from the island rule, a numerical 21/2-layer reduced-gravity model of the Pacific Ocean is driven by the FSU winds. Although the modeled NHRC does not match the ADCP observations in every detail, the mean transport and some aspects of the variability are similar: the model shows the 1991 transition and lacks an annual cycle. Experiments with and without temporal wind variability near the equator show that the NHRC is governed primarily by winds east of the Hawaiian Islands; equatorial winds have little effect. Nonlinearity is shown to be important.
\end{abstract}

\section{Introduction}

Starting with the climatological XBT analysis by White (1983), it has gradually become apparent that there is a long-term mean flow to the northwest along the northeast side of the Hawaiian Islands: the North Hawaiian Ridge Current (NHRC). Using repeated shipboard acoustic Doppler current profiler (ADCP) measurements from Oahu to station ALOHA of the Hawaii Ocean Time-series (HOT) program (see Fig. 1 for locations), Firing (1996) showed that the mean NHRC across this section has a maximum speed of $0.17 \mathrm{~m} \mathrm{~s}^{-1}$ and a width of about $100 \mathrm{~km}$, extending from Oahu to ALOHA. While these results were based on 30 HOT cruises over a 5-yr period (1988-93), averaging the ADCP measurements over the 58 cruises from 1988 to

* SOEST Contribution Number 4851.

Corresponding author address: Dr. Eric Firing, Department of Oceanography, University of Hawaii at Manoa, 1000 Pope Road, Honolulu, HI 96822.

E-mail: efiring@soest.hawaii.edu
1996 gives a similar picture (Fig. 2). The 8-yr mean core speed of the NHRC is $0.15 \mathrm{~m} \mathrm{~s}^{-1}$. By analyzing the long-term surface drifter data from the WOCE Surface Velocity Program and NOAA's Pelagic Fisheries Research Program, Qiu et al. (1997a) showed that the NHRC is the northern branch of a westward-moving interior flow, which bifurcates east of the island of Hawaii. They went on to show that the mean NHRC can be modeled as a simple western boundary current consistent with Godfrey's "Island Rule" (Godfrey 1989); the rectification of reflected and incident Rossby waves, initially suggested by Mysak and Magaard (1983), is neither necessary nor efficacious. [See Qiu et al. (1997a) and Firing (1996) for a more detailed review of NHRC observations and theories.]

The reason it took many years to establish the existence of a mean NHRC is that it is a weak feature, often overwhelmed by mesoscale eddies or even absent owing to interannual variability. For example, Fig. 3 shows the time series of NHRC transport in a shallow layer (10$170 \mathrm{~m}$ ) from 58 HOT cruises. The standard deviation, $1.4 \mathrm{~Sv}\left(\mathrm{~Sv} \equiv 10^{6} \mathrm{~m}^{3} \mathrm{~s}^{-1}\right)$, is only slightly less than the mean transport, $2.0 \mathrm{~Sv}$. The NHRC is sometimes absent or reversed, as has also been noted by Price et al. (1994) 


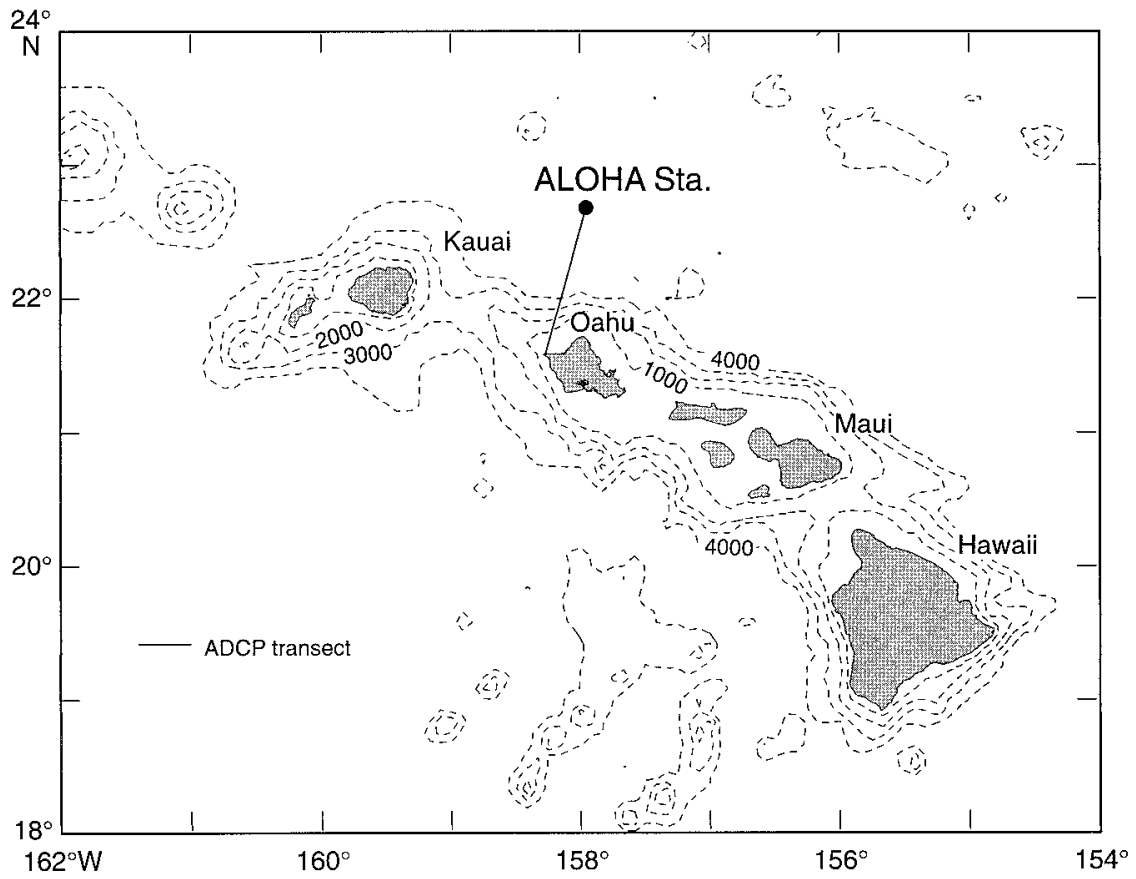

FIG. 1. Bottom topography in the vicinity of the Hawaiian Islands, contoured at 1000-m intervals. The solid line north of Oahu is the ADCP transect from the HOT cruises.

and Bingham (1998) in their respective analyses using XBT and mechanical BT data. Notice that the timescale of the transport fluctuations in Fig. 3 ranges from intraseasonal to interannual, but there is no clear annual cycle. In sharp contrast, the trade winds east of the Hawaiian Islands have a strong annual cycle (Wyrtki and Meyers 1976). Striking features of the time series include relatively consistent and strong transport prior to late 1991; a prolonged reversal in late 1991 and early 1992, with relatively weak transport continuing until early 1994; higher transports in 1994 and early 1995 broken by a very brief reversal in February 1995; and a transport peak in mid 1996.

The objective of this study is to characterize the variability of the NHRC and to provide a theoretical basis for understanding the causes of this variability. We begin with a novel version of the island rule, including time dependence and stratification; we emphasize the distinction between the ocean interior and the vicinity of the island, and we concentrate on upper-layer transport rather than barotropic transport. We treat baroclinic Rossby waves explicitly, but ignore topography, nonlinearity, and the finite thickness of the western boundary current. The original island rule was steady and baroclinic (Godfrey 1989). It required a depth of no motion (or a flat ocean bottom), with no topography extending above that depth. Wajsowicz (1993, 1994, 1995) relaxed these constraints and discussed baroclinic Rossby wave effects, modeling them numerically but not analytically. Her emphasis was on depth-averaged flow over sills, and in particular the Indonesian
Throughflow. Most recently, Pedlosky et al. (1997) have exhaustively explored the island rule in a primarily barotropic context with nonlinearity and finite-boundary layer thickness.

To relax the strict assumptions required by our timedependent island rule (TDIR), we use the 21/2-layer model of Qiu et al. (1997a) driven by The Florida State University (FSU) winds to hindcast the NHRC time series. Although the hindcast is not a close match to the ADCP time series, there is sufficient resemblance to suggest that the model is capturing much of the important physics.

\section{The upper-layer time-dependent island rule}

Qiu et al. (1997a) showed that the mean NHRC is a western boundary current as described by Godfrey's (1989) island rule. In the usual derivation (see also, e.g., Pedlosky et al. 1997), the boundary current transport $\left(T_{\mathrm{bc}}\right)$ is calculated as the difference between the total meridional flow between the island and the continent to the east $\left(T_{t}\right)$ and the interior flow $\left(T_{i}\right)$. This is particularly convenient for the steady case because $T_{t}$ is then a constant that can be calculated by integrating the momentum balance along a contour extending from the eastern boundary westward to the north tip of the island, around the west coast of the island, east from the south tip of the island to the continent, and then along the ocean's eastern boundary back to the starting point. The interior flow is calculated as a function of latitude using the Sverdrup balance. 
Mean of 58 cruises, 1988-1996

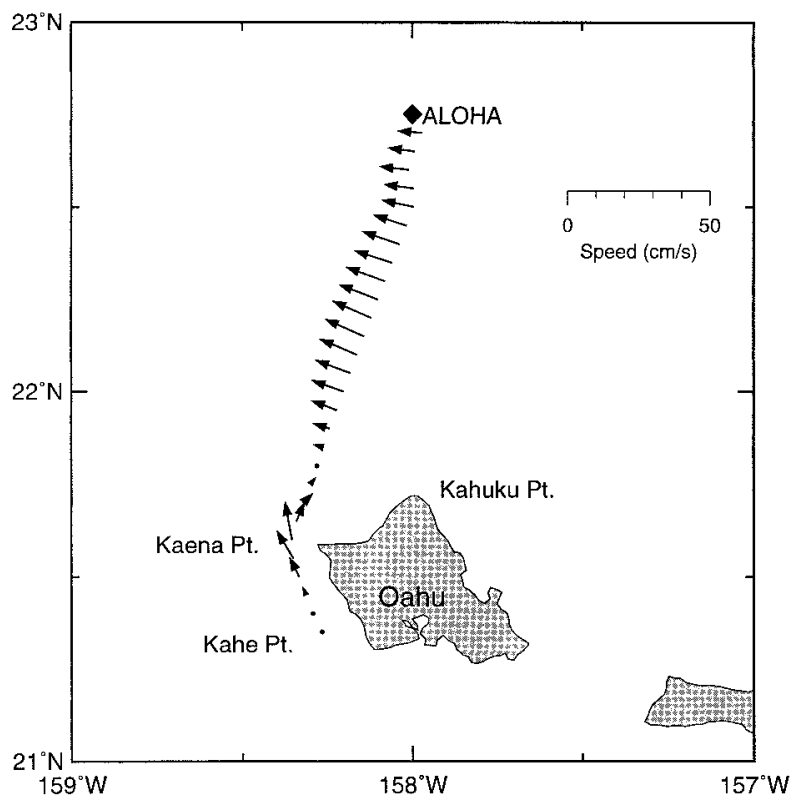

FIG. 2. Velocity from the HOT ADCP sections, 1988 to 1996, averaged from 20 to $120 \mathrm{~m}$. The core speed of the NHRC for this depth average is $0.15 \mathrm{~m} \mathrm{~s}^{-1}$.

Although it is computationally convenient and mathematically elegant, this form of the derivation may obscure the physics; it lumps two physically dissimilar regions, the interior and the western boundary, together in the calculation of $T_{t}$. We prefer to explicitly separate the ocean into a large interior region and a small island region (Fig. 4). The latter includes the western boundary current and the eastern boundary of the island. Just like the western boundary region in a simple basin, the island region is driven by local winds (typically minor) and by the interior flow at the seaward edge of the western boundary current; that is, the western boundary current responds to the interior flow. The interior region, in turn, is wind driven, completely independent of the presence of the island. Because the island region is small (i.e., the western boundary current is narrow), we can neglect storage there, even in the time-dependent baroclinic

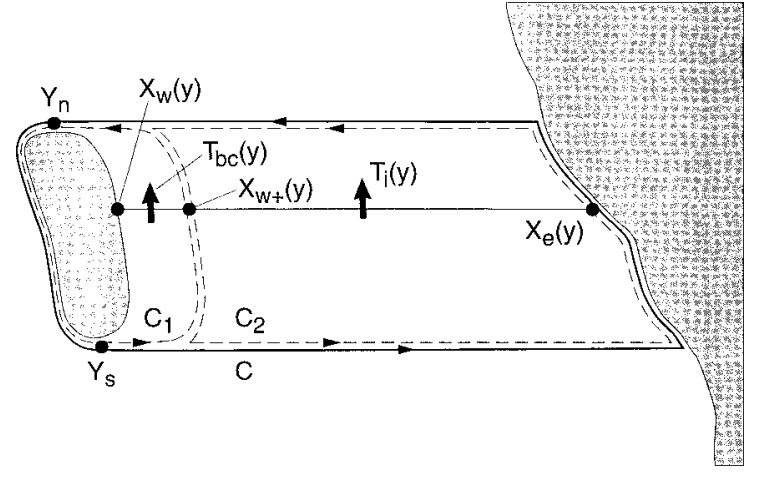

FIG. 4. Schematic defining integration contours for the island rule: $y_{s}$ and $y_{n}$ are the latitudes of the southern and northern tips of the island, $x_{w}(y)$ and $x_{e}(y)$ are the longitudes of the island's west coast and the ocean's eastern boundary at latitude $y$, and $x_{w+}(y)$ is the offshore edge of the island's western boundary layer. The interior meridional transport between $x_{w+}$ and $x_{e}$ is $T_{i}(y)$, and the meridional transport of the boundary current is $T_{\mathrm{bc}}(y)$.

case. Any flow from the interior into the western boundary must be deflected north or south; the only question is how much goes north and how much goes south. We will show that the answer is determined by the vorticity balance in the island region.

To extend the island rule to the time-dependent case in the simplest way that retains both barotropic and baroclinic processes, we adopt a linearized, hydrostatic, Boussinesq 2-layer model. Focusing on seasonal and longer time scales, and on spatial scales longer than the baroclinic Rossby radius of deformation (approximately $60 \mathrm{~km}$ ) outside the western boundary region, we further adopt the long Rossby wave approximation, that is, neglect of the acceleration terms in the momentum balance. The long-wave approximation eliminates short Rossby waves and makes the long Rossby waves nondispersive; group velocity is purely zonal (see, e.g., Gill 1982). At annual and shorter periods this degrades the quantitative accuracy of the theory, but it does not substantially change the qualitative physics. A second effect of neglecting acceleration is to make Kelvin wave adjustments instantaneous. Given that a baroclinic Kelvin wave can circle the Hawaiian Islands in about 3 days,

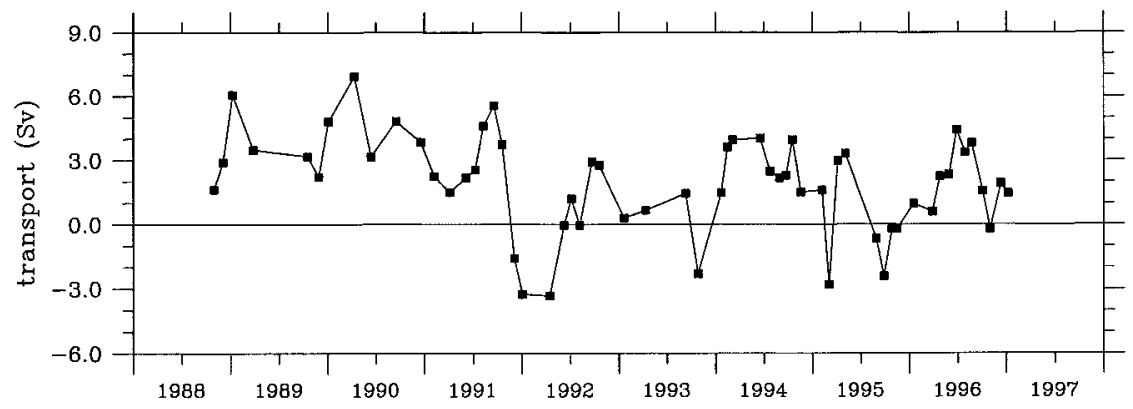

FIG. 3. Time series of the NHRC transport integrated from 10 to $170 \mathrm{~m}$ for each HOT cruise. The mean is $2.0 \mathrm{~Sv}$ and the standard deviation is $1.4 \mathrm{~Sv}$. 


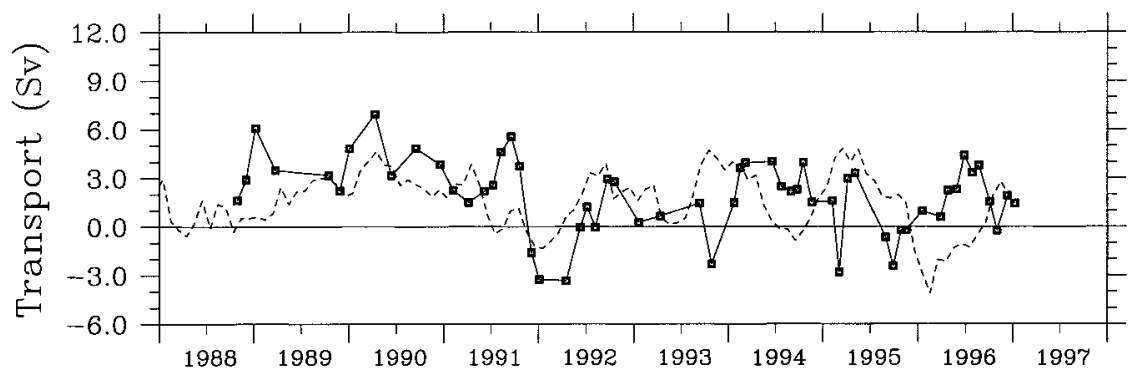

FIG. 5. ADCP NHRC transport time series (solid line and squares) compared to the 2-layer time-dependent island rule calculation (dashed) from the FSU winds and using Rossby wave speed calculated with a constant gravity wave speed, $2.6 \mathrm{~m} \mathrm{~s}^{-1}$.

this is a very good aproximation for the timescales of interest here.

With these approximations, our model equations are

$$
\begin{aligned}
f \mathbf{k} \times \mathbf{u}_{1} & =-g \boldsymbol{\nabla} \eta_{1}+\frac{\boldsymbol{\tau}_{w}(t)}{\rho_{0} H_{1}}+F\left(\mathbf{u}_{1}\right) \\
\frac{\partial \eta_{1}}{\partial t}-\frac{\partial \eta_{2}}{\partial t}+H_{1} \boldsymbol{\nabla} \cdot \mathbf{u}_{1} & =0 \\
f \mathbf{k} \times \mathbf{u}_{2} & =-g \boldsymbol{\nabla} \eta_{1}-g^{\prime} \boldsymbol{\nabla} \eta_{2}+F\left(\mathbf{u}_{2}\right) \\
\frac{\partial \eta_{2}}{\partial t}+H_{2} \boldsymbol{\nabla} \cdot \mathbf{u}_{2} & =0,
\end{aligned}
$$

where $\eta_{i}$ is the upward displacement of the top of the $i$ th layer from its equilibrium position, $H_{i}$ is the mean $i$ th layer thickness, $g$ is the acceleration of gravity, $g^{\prime}$ $\equiv g \delta \rho / \rho_{0}, \delta \rho \equiv \rho_{2}-\rho_{1}$, and $F\left(\mathbf{u}_{i}\right)$ represents the horizontal momentum dissipation in the form of interfacial friction and/or horizontal eddy diffusion. To stress that the wind forcing here is time-dependent, we denoted the wind stress vector in Eq. (1) by $\boldsymbol{\tau}_{w}(t)$.

The wave dynamics of this system are clarified by writing it in terms of vertical normal modes. We arbitrarily normalize the velocity modes by the layer- 1 velocity, so they are denoted by $\mathbf{u}_{M i} \equiv \mathbf{u}_{1}+\alpha_{i} \mathbf{u}_{2}$. Mode displacements are then defined as

$$
\eta_{M i} \equiv \eta_{1}+\eta_{2} \frac{\alpha_{i}}{\left(1+\alpha_{i}\right)} \frac{\delta \rho}{\rho_{0}} .
$$

For the barotropic mode, $\alpha_{0} \approx H_{2} / H_{1}$; for the baroclinic mode,

$$
\alpha_{1} \approx-1+\frac{\delta \rho}{\rho_{0}} \frac{H_{2}}{H_{1}+H_{2}},
$$

where the second term is important only in factors of $\left(1+\alpha_{1}\right)$. In terms of these modes, the momentum and continuity equations are

$$
f \mathbf{k} \times \mathbf{u}_{M i}=-g\left(1+\alpha_{i}\right) \boldsymbol{\nabla} \eta_{M i}+\frac{\boldsymbol{\tau}_{w}(t)}{\rho_{0} H_{1}}+F\left(\mathbf{u}_{M i}\right)
$$

$\frac{\partial \eta_{M i}}{\partial t}+H_{1} \boldsymbol{\nabla} \cdot \mathbf{u}_{M i}=0$
The corresponding vorticity equation for each mode in the interior, neglecting lateral friction, is

$$
\frac{\partial \eta_{M i}}{\partial t}+c_{R i} \frac{\partial \eta_{M i}}{\partial x}=-\nabla \times\left(\frac{\boldsymbol{\tau}_{w}}{\rho_{0} f}\right) \equiv B(x, y, t),
$$

where $c_{R i} \equiv-\beta g H_{1}\left(1+\alpha_{i}\right) / f^{2}$ is the zonal component of the phase velocity of long Rossby waves for mode $i$. Note that $c_{R i}$ is defined here to be negative, that is, minus the speed. Equation (7) can be solved by integrating $B(x, y, t)$ along the Rossby wave characteristic, which is zonal under the long-wave approximation:

$$
\begin{aligned}
\eta_{M i}(x, y, t)= & \eta_{M 1}\left(x_{e}, y, t-\frac{x-x_{e}}{c_{R i}}\right) \\
& +\frac{1}{c_{R i}} \int_{x_{e}}^{x} B\left(x^{\prime}, y, t-\frac{x-x^{\prime}}{c_{R i}}\right) d x^{\prime},
\end{aligned}
$$

where $x_{e}(y)$ is the longitude of the eastern boundary. The first term on the right is the nondispersive zonal propagation of eastern boundary pressure changes, such as might be caused by the passage of a coastal Kelvin wave; the second term includes all effects of wind forcing and the no-normal-flow boundary condition at the eastern boundary.

Consider the simplest interesting special case of (8): the response to wind forcing that is sinusoidal in time and uniform in $x$, that is, $B=B_{0}(y) \exp (i \omega t)$. From the second term in (8) we then get

$$
\eta_{M i}=\frac{B_{0} \exp (i \omega t)}{i \omega}\left[1-\exp \left(\frac{i \omega}{c_{R i}}\left(x_{e}-x\right)\right)\right],
$$

consisting of a zonally uniform Ekman pumping response plus a free Rossby wave generated at the eastern boundary to satisfy the boundary condition of no normal flow. For $\left(x_{e}-x\right) \ll\left|c_{R i}\right| / \omega$, this becomes the Sverdrup balance, the solution to (7) without the time-dependent (vortex stretching) term. This is an excellent approximation for the barotropic mode for the intraannual and longer time scales of interest here; $c_{R 0}=-\beta g\left(H_{1}+\right.$ $\left.\mathrm{H}_{2}\right) / f^{2} \approx-400 \mathrm{~m} \mathrm{~s}^{-1}$ is effectively infinite, as in the rigid-lid approximation that we will use. (Without the long-wave approximation, the barotropic wave speed is 
much slower, but still fast enough to justify being approximated as infinite. A large-scale barotropic Rossby wave travels from North America to Hawaii in less than 10 days.) For the first baroclinic mode, $c_{R 1}=$ $-\beta g \delta \rho H_{1} H_{2} / f^{2}\left(H_{1}+H_{2}\right) \approx-0.06 \mathrm{~m} \mathrm{~s}^{-1}$. For annual forcing the wavelength is about $1100 \mathrm{~km}$, so the Sverdrup balance applies only for distances from the eastern boundary much less than $180 \mathrm{~km}$.

\section{a. Interior transport $T_{i 1}(y, t)$} is

The upper-layer interior transport east of the island

$$
T_{i 1}(y, t) \equiv \int_{x_{w+}(y)}^{x_{e}(y)} H_{1} v_{1} d x
$$

where $x_{w+}(y)$ denotes the $x$ position just offshore of the western boundary current (see Fig. 4). Expressing $v_{1}$ in terms of the mode amplitudes and then using Eqs. (5) and (8) together with the rigid-lid approximation, this becomes

$$
\begin{aligned}
T_{i 1}(y, t)= & \int_{x_{e}}^{x_{w+}} \frac{\tau_{w}^{x}}{f \rho} d x^{\prime} \\
& +\frac{f}{\beta} \frac{H_{1}}{H_{1}+H_{2}} \int_{x_{e}}^{x_{w+}} B\left(x^{\prime}, y, t\right) d x^{\prime} \\
& +\frac{f}{\beta} \frac{H_{2}}{H_{1}+H_{2}} \int_{x_{e}}^{x_{w+}} B\left(x^{\prime}, y, t-\frac{x-x^{\prime}}{c_{R 1}}\right) d x^{\prime} \\
& -\frac{g}{f} \frac{H_{1} H_{2}^{2}}{H_{1}+H_{2}} \frac{\delta \rho}{\rho}\left[\eta_{M 1}\left(x_{e}, y, t\right)\right. \\
& \left.-\eta_{M 1}\left(x, y, t-\frac{x-x_{e}}{c_{R 1}}\right)\right],
\end{aligned}
$$

where $\tau_{w}^{x}$ is the $x$ component of the wind stress vector. The first term in Eq.(11) is the meridional component of the Ekman transport; the second is the upper-layer fraction of the barotropic Sverdrup transport, based on the time-varying wind stress curl; the third term is the net transport associated with the baroclinic response to Ekman pumping, including both the local response and a Rossby wave component; and the fourth term is the net transport due to Rossby waves generated by baroclinic disturbances at the eastern boundary, such as coastal Kelvin waves.

\section{b. Meridional transport of the boundary current $T_{b c l}(y, t)$}

With $x_{w}(y)$ denoting the $x$ position of the island's east coast, the upper-layer meridional transport of the boundary current is

$$
T_{\mathrm{bc} 1}(y, t) \equiv \int_{x_{w}(y)}^{x_{w+}(y)} H_{1} v_{1} d x
$$

Assuming the boundary current region is narrow, changes in upper-layer volume can be neglected in the mass balance for the timescales of interest. The mass balance then can be integrated over the boundary current region to give

$$
T_{\mathrm{bc} 1}\left(y_{n}, t\right)-T_{\mathrm{bcl}}\left(y_{s}, t\right)+\int_{C_{w+}} H_{1} \mathbf{u}_{1} \cdot d \mathbf{l}=0,
$$

where $C_{w+}$ is the segment of $C_{1}$ that runs along the offshore edge of the boundary current, $x=x_{w+}$ from $y_{s}$ to $y_{n}$ (Fig. 4). More generally, replacing $y_{s}$ with $y$, the mass balance gives $T_{\mathrm{bc} 1}(y, t)$ in terms of a single transport, $T_{\mathrm{bc} 1}\left(y_{n}, t\right)$, and the flux through $x_{w+}$ between $y$ and $y_{n}$.

To determine $T_{\mathrm{bc} 1}\left(y_{n}, t\right)$, a vorticity constraint must be added. It can be derived by integrating the momentum equation (1) around contour $C_{1}$. This contour transits ocean interior or island eastern boundary regions, where dissipation and nonlinearity are negligible, except for the short segments near $y_{n}$ and $y_{s}$. Following Godfrey (1989) we neglect dissipation in those segments as well, obtaining

$$
\oint_{C_{1}} f \mathbf{k} \times \mathbf{u}_{1} \cdot d \mathbf{l}=\oint_{C_{1}} \frac{\boldsymbol{\tau}_{w}(t) \cdot d \mathbf{l}}{\rho_{0} H_{1}} .
$$

Using $f=f_{s}+\beta\left(y-y_{s}\right)$ and recognizing $\oint_{C_{1}} \mathbf{k} \times \mathbf{u}_{1}$ - $d \mathbf{l}=0$ because of mass conservation, we can rewrite Eq. (14) as follows:

$$
\begin{aligned}
& \qquad \beta \oint_{C_{1}} y \mathbf{k} \times \mathbf{u}_{1} \cdot d \mathbf{l}=\oint_{C_{1}} \frac{\boldsymbol{\tau}_{w} \cdot d \mathbf{l}}{\rho_{0} H_{1}}, \\
& \text { or } \\
& y_{n} T_{\mathrm{bc} 1}\left(y_{n}, t\right)-y_{s} T_{\mathrm{bc} 1}\left(y_{s}, t\right)+\int_{C_{w+}} y H_{1} \mathbf{k} \times \mathbf{u}_{1} \cdot d \mathbf{l} \\
& =\oint_{C_{1}} \frac{\boldsymbol{\tau}_{w} \cdot d \mathbf{l}}{\rho_{0} \beta} .
\end{aligned}
$$

By eliminating $T_{\mathrm{bc} 1}\left(y_{s}, t\right)$ from Eqs. (13) and (16) and dividing by $\Delta y \equiv y_{n}-y_{s}$, we have

$$
\begin{aligned}
& T_{\mathrm{bc} 1}\left(y_{n}, t\right) \\
& \quad=\frac{1}{\Delta y} \oint_{C_{1}} \frac{\boldsymbol{\tau}_{w} \cdot d \mathbf{l}}{\beta \rho_{0}}-\frac{1}{\Delta y} \int_{C_{w+}}\left(y-y_{s}\right) H_{1} \mathbf{k} \times \mathbf{u}_{1} \cdot d \mathbf{l} .
\end{aligned}
$$

This is the most physically meaningful expression for the boundary current transport.

The first term on the rhs of (17) gives the response to local wind forcing around the island. A circulating component of the wind generates a western boundary current with the same sense of circulation. For example, 
a southward wind along the western side of the island sets up a pressure gradient with high pressure to the south; on the eastern side of the island, this northward pressure gradient force is balanced by friction in a northward western boundary current. A northward wind along the eastern side of the island is balanced directly by friction in a northward western boundary current so that it does not impose a pressure difference between the north and south ends of the island.

The second term on the rhs of (17) gives the western boundary response to the ocean interior, east of the current. Together with (13), this vorticity constraint says that in the absence of circumisland wind an inflow to the boundary current at latitude $y$ will split, with fraction $\left(y-y_{s}\right) /\left(y_{n}-y_{s}\right)$ going north and the remainder going south.

Now we need only calculate the inflow from the interior using (11), (8), and conservation of mass. Starting with the latter, we integrate (2) zonally from $x_{w+}$ to the basin's eastern boundary:

$$
\begin{aligned}
& H_{1}\left(u_{1}\left(x_{w+}\right)-v_{1}\left(x_{w+}\right) \frac{d x_{w+}}{d y}\right) \\
& =-\int_{x_{w+}}^{x_{e}} \frac{\partial \eta_{2}}{\partial t} d x+\frac{\partial}{\partial y} T_{i 1}(y, t) .
\end{aligned}
$$

Multiplying Eq. (18) by $\left(y-y_{s}\right)$, integrating in $y$, and substituting in Eq. (17) gives

$$
T_{\mathrm{bc1}}\left(y_{n}, t\right)=\frac{1}{\Delta y} \oint_{C_{1}} \frac{\boldsymbol{\tau}_{w} \cdot d \mathbf{l}}{\rho_{0} \beta}+\frac{1}{\Delta y} \int_{y_{s}}^{y_{n}} \int_{x_{w+}}^{x_{e}}\left(y-y_{s}\right) \frac{\partial \eta_{2}}{\partial t} d x d y+\left[\frac{1}{\Delta y} \int_{y_{s}}^{y_{n}} T_{i 1}(y, t) d y-T_{i 1}\left(y_{n}, t\right)\right] .
$$

The first rhs term is again the local wind forcing. The second term, depending on the rate of change of averaged upper-layer thickness, can be called a "storage" term; it vanishes in the low-frequency limit. The third term, present at all frequencies including zero, is the meridionally averaged interior meridional transport minus the local interior meridional transport at $y_{n}$. We will call it the "interior transport" term. This third term is a small difference of large numbers, but it is best thought of as a whole rather than as the sum of its parts; recall that it comes from the latitude-weighted integral of the flow into the western boundary region from the interior, the second term in Eq. (17). It is only as a practical matter, to calculate this inflow from the wind field, that we must consider the parts separately. We emphasize that the names given to the storage and interior transport terms are simply convenient tags rather than accurate labels for the dynamical roles of the terms; the dynamics of the boundary current transport is expressed much more clearly in Eq. (17) than in Eq. (19).

To calculate the boundary current transport at other latitudes, we neglect mass storage in the narrow boundary current region, so a simple mass balance yields

$$
\begin{aligned}
T_{\mathrm{bc} 1}(y, t)= & T_{\mathrm{bc} 1}\left(y_{n}, t\right)+T_{i}\left(y_{n}, t\right)-T_{i}(y, t) \\
& -\int_{y}^{y_{n}} \int_{x_{w+}}^{x_{e}} \frac{\partial \eta_{2}}{\partial t} d x d y .
\end{aligned}
$$

In Eqs. (20) and (19) we calculate the interior transport terms from Eq. (11) and note that the interface height $\eta_{2}$ is governed entirely by the first baroclinic mode, as calculated from Eq. (8). Hence, the upper-layer western boundary current transport at any latitude can be calculated from the time history of the wind field around and to the east of the island, together with the time history of the interface height along the eastern boundary.

\section{c. Application of the TDIR to the NHRC}

To apply this simple TDIR to the NHRC, we make two additional approximations: we ignore fluctuations in interface height along the eastern boundary and we assume that the islands from Hawaii to Oahu act as a single island with $y_{s}=18.9^{\circ} \mathrm{N}$ and $y_{n}=21.8^{\circ} \mathrm{N}$ (Fig. 1). For comparison with the ADCP data taken near the northern end of Oahu, we will focus on the NHRC transport predicted by the time-dependent island rule along $y=y_{n}$, namely, $T_{\mathrm{NHRC}}(t)=T_{\mathrm{bc} 1}\left(y_{n}, t\right)$ evaluated from Eq. (19). The wind field used in the calculation is the FSU monthly product (Goldenberg and O'Brien 1981) on a $2^{\circ}$ grid. The calculation was done with a Rossby wave speed calculated two ways: using a uniform gravity wave speed of $2.6 \mathrm{~m} \mathrm{~s}^{-1}$ and letting the gravity wave speed decrease linearly from $2.8 \mathrm{~m} \mathrm{~s}^{-1}$ at Hawaii to 2.2 $\mathrm{m} \mathrm{s}^{-1}$ at the California coast. The results were similar, and only the constant speed case is shown here. The calculated NHRC time series bears little resemblance to the ADCP transports (Fig. 5), apart from similar means, amplitudes, and timescales of variability. Both are variable at annual and interannual periods, but with no regular annual cycle. Both show consistently positive transports in 1989-90, followed by increased variability and more frequent reversals. Individual maxima and minima, or reversals, do not match between the two time series.

Despite the lack of correspondence in detail between the TDIR prediction and the ADCP transports, we believe the TDIR contains an important kernel of relevant physics on which any more complicated theory or model 

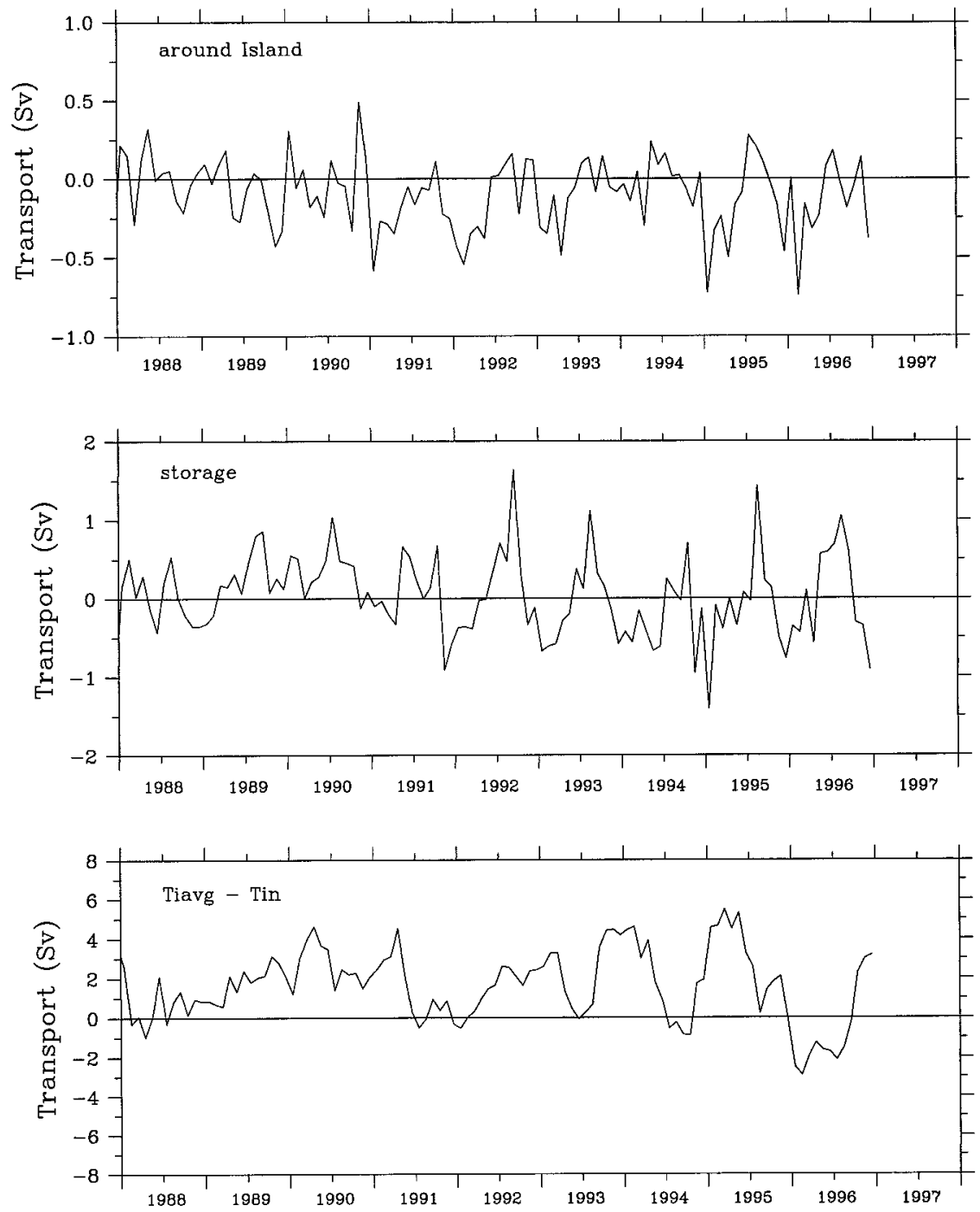

FIG. 6. The three basic terms contributing to the TDIR calculation as in Fig. 5, based on Eq. (19): the local forcing term (top); the "storage" term (middle); and the "interior transport" term (bottom), by far the most important of the three. See text for explanation of the terms.

must be built. It is therefore worthwhile to examine the terms in the TDIR before proceeding to a numerical model. The time series of the three terms in Eq. (19) show that the local forcing is unimportant, usually contributing less than $0.5 \mathrm{~Sv}$ (Fig. 6). The storage term is larger than the local term, but still small, with peak values of about $1.5 \mathrm{~Sv}$ and typical values of $0.5 \mathrm{~Sv}$. By far the most important is the interior transport term. It accounts for most of the mean and the variability. This term can be subdivided by substituting the first three terms in Eq. (11); we are ignoring the fourth term. The Ekman term contributes about $1 \mathrm{~Sv}$ to the mean and varies mostly between zero and two; it is small but not negligible (Fig. 7). The upper-layer fraction of the barotropic geostrophic response is near zero on average and has high-frequency fluctuations of amplitude $0.5-1$ $\mathrm{Sv}$; it is negligible. The baroclinic geostrophic response is by far the largest of the three, and looks much like a smoothed version of the total TDIR NHRC transport; it is the smoothest of all the TDIR terms.

The lack of similarity in detail between the observed NHRC and the TDIR prediction raises the obvious question as to the reason. First, we look at sensitivity of the calculation to the particular wind product. Comparing the TDIR NHRC from FSU winds to that from the NCEP reanalysis (Kalnay et al. 1996) we see no more resemblance than between the FSU TDIR and the NHRC observations (Fig. 8). The Ekman transport term is fairly similar between the FSU calculation (Fig. 7) and the NCEP calculation (not shown), indicating that the zonally integrated winds are also similar. The much larger difference in the main contributor to the NHRC variability, the baroclinic geostrophic response, suggests that differences in the zonal structure of the two wind 

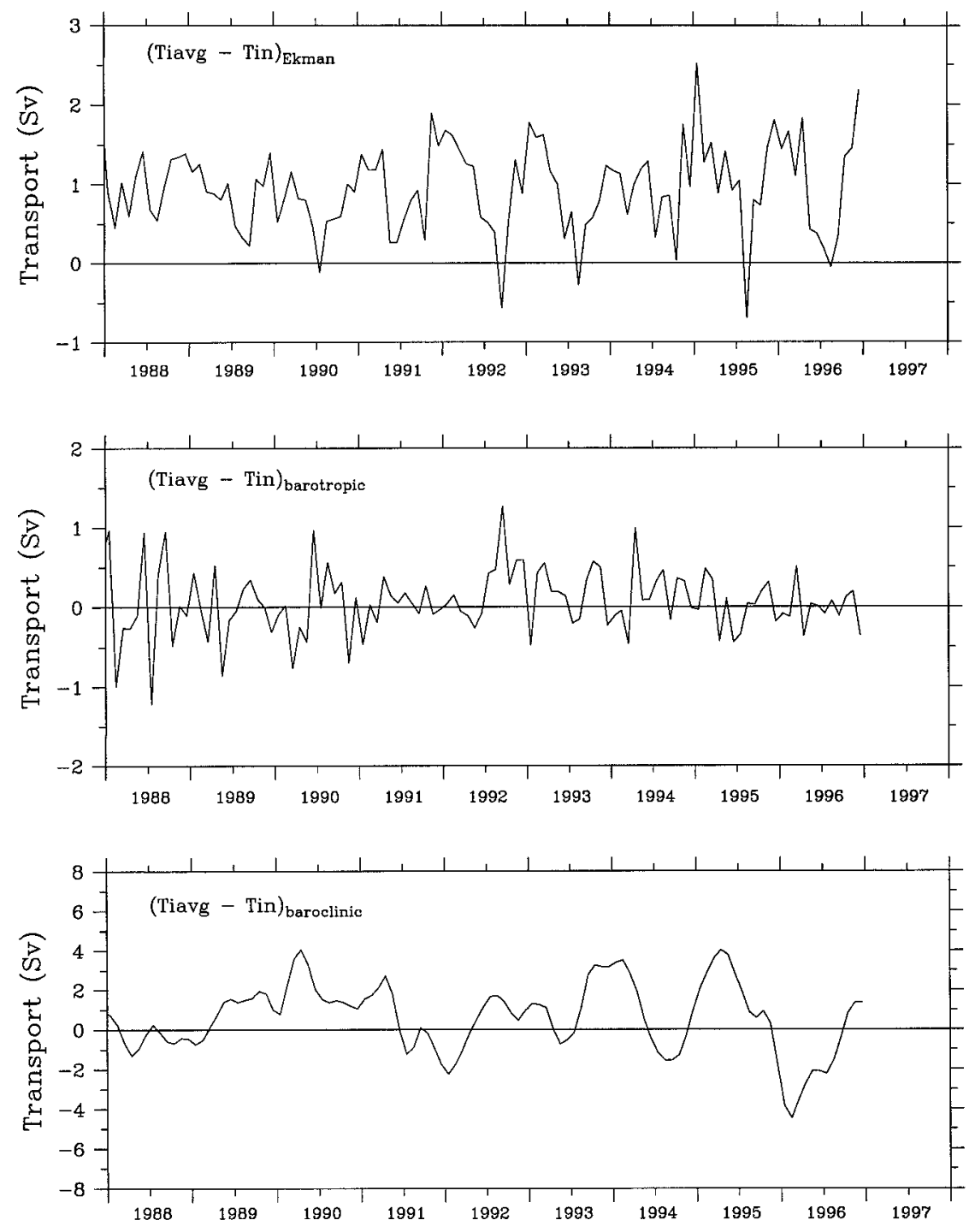

FIG. 7. Breakdown of the "interior transport" term from Fig. 6 into an Ekman transport component (top), the upper-layer fraction of the quasi-steady barotropic geostrophic transport (middle), and the baroclinic geostrophic transport (bottom). The latter is dominant but the Ekman term is not negligible, particularly in the mean.

products are responsible for their differing TDIR predictions. Interestingly, the NCEP prediction, unlike the FSU prediction and the observations, has a regular annual cycle. We have not investigated the reason for this difference.

Sensitivity of the TDIR NHRC to details in the wind field suggests that NHRC variability may not be predictable from any of the typical wind products. Nevertheless, we may be curious as to the sensitivity of the NHRC to any of the many approximations used in the TDIR: the long-wave approximation, the neglect of friction and nonlinearity, the simplification of the stratification to two layers, and the neglect of eastern boundary variability such as that caused by equatorial winds. To relax these approximations, we now turn to a numerical model.

\section{Numerical model}

To simulate the variability of the ocean circulation around the Hawaiian Islands, we adopt a 21/2-layer, reduced-gravity model that covers the tropical and subtropical region of the North Pacific. Though simple in its formulation, the $2^{1 / 2}$-layer reduced-gravity model is suitable for studying the interior wind-driven circulation and the propagation of baroclinic Rossby waves (McCreary and Lu 1994). Selection of a reduced gravity model is motivated by the result of the previous section, 


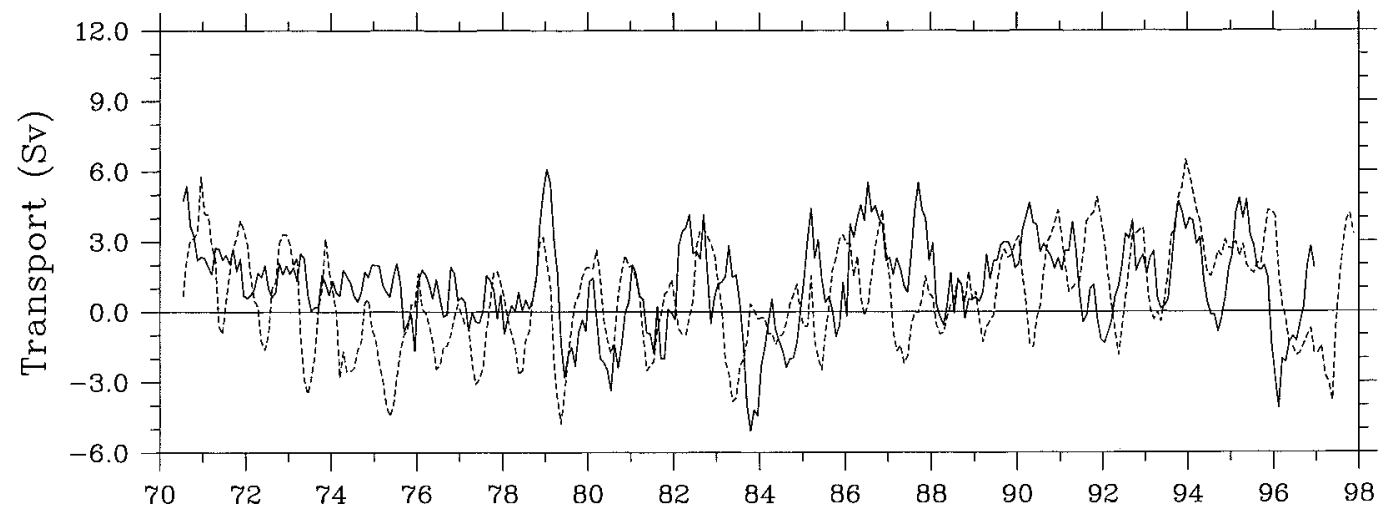

FIG. 8. Comparison between the 2-layer TDIR calculations based on FSU winds (solid line) versus NCEP winds (dashed). There are major differences both in detail (features that do not match) and in character (stronger and more consistent annual cycle in the NCEP calculation).

that the barotropic mode plays a negligible role in the TDIR estimate of the NHRC; we have no reason to expect that additional processes in the numerical model, such as friction and nonlinearity, would make the barotropic mode nonnegligible. By using two active layers rather than one, we can obtain a reasonably accurate simulation of the subtropical gyre, particularly in the vicinity of the Hawaiian Islands. In earlier 11/2-layer simulations, the single active layer became too shallow and too swift in the northern part of the gyre, causing the streamlines to impinge on the Hawaiian Islands at an unrealistic angle.

\section{a. Configuration}

In the 21/2-layer reduced-gravity system (which assumes the third layer is infinitely deep), equations governing the upper two layers of the ocean can be written as follows:

$$
\begin{gathered}
\frac{\partial \mathbf{u}_{1}}{\partial t}+\mathbf{u}_{1} \cdot \boldsymbol{\nabla} \mathbf{u}_{1}+f \mathbf{k} \times \mathbf{u}_{1} \\
=-g_{13}^{\prime} \boldsymbol{\nabla} h_{1}-g_{23}^{\prime} \boldsymbol{\nabla} h_{2}+\frac{\boldsymbol{\tau}_{w}-\boldsymbol{\tau}_{s}}{\rho_{0} h_{1}}+A_{h} \nabla^{2} \mathbf{u}_{1} \\
\frac{\partial h_{1}}{\partial t}+\nabla \cdot\left(h_{1} \mathbf{u}_{1}\right)=w_{e} \\
\frac{\partial \mathbf{u}_{2}}{\partial t}+\mathbf{u}_{2} \cdot \nabla \mathbf{u}_{2}+f \mathbf{k} \times \mathbf{u}_{2} \\
=-g_{23}^{\prime} \boldsymbol{\nabla}\left(h_{1}+h_{2}\right)+\frac{\boldsymbol{\tau}_{s}}{\rho_{0} h_{2}}+A_{h} \nabla^{2} \mathbf{u}_{2} \\
\frac{\partial h_{2}}{\partial t}+\nabla \cdot\left(h_{2} \mathbf{u}_{2}\right)=-w_{e}
\end{gathered}
$$

where $\mathbf{u}_{i}$ is the velocity vector in the $i$ th layer, $h_{i}$ is the $i$ th layer thickness, $\mathbf{k}$ is a unit vector in the vertical direction, $\nabla^{2}$ is the horizontal Laplacian operator, $A_{h}$ is the coefficient of horizontal eddy viscosity, and $\rho_{0}$ is the reference water density. The Coriolis parameter $f$ $\equiv 2 \Omega \sin \theta$, where $\Omega$ is the earth's rotation rate and $\theta$ is the latitude. The reduced gravity between the $i$ th and $j$ th layers is $g_{i j}^{\prime} \equiv\left(\rho_{j}-\rho_{i}\right) g / \rho_{\mathrm{O}}$, and $\boldsymbol{\tau}_{w}$ is the wind stress vector. Following O'Brien and Hurlburt (1982), the interfacial shear stress vector is given by

$$
\boldsymbol{\tau}_{s}=\rho_{0} C\left(\mathbf{u}_{1}-\mathbf{u}_{2}\right)\left(\left|\mathbf{u}_{1}\right|+\left|\mathbf{u}_{2}\right|\right) / 2,
$$

where $C$ is the interfacial drag coefficient $(C=5 \times$ $\left.10^{-4}\right)$. In the continuity equations (22) and (24), $w_{e}$ denotes the entrainment velocity. The numerical treatment for the entrainment, which takes place when the upperlayer thickness becomes shallower than $80 \mathrm{~m}$, follows that described by McCreary and Lu (1994).

To minimize effects of specifying artificial boundary values, the model domain is chosen to include the tropical and the northern subtropical circulations of the Pacific Ocean from $10^{\circ} \mathrm{S}$ to $42^{\circ} \mathrm{N}$. The model basin is bounded to the west by the Asian continent and to the east by the North and South American continents (see Fig. 9a). Along the model's northern and southern boundaries, a free-slip condition is used. A nonslip condition is used along the coast or marginal seas (depth $<200 \mathrm{~m}$ ). To focus on the NHRC, the model grid has its finest horizontal resolution of $0.1^{\circ} \times 0.1^{\circ}$ around the Hawaiian Islands, and the grid resolution decreases gradually away from the islands to $12^{\circ}$ in latitude and $2 / 3^{\circ}$ in longitude at the model boundary regions. The horizontal eddy viscosity coefficient $A_{h}=500 \mathrm{~m}^{2} \mathrm{~s}^{-1}$. The reduced gravity constants and the model's initial layer thicknesses are $g_{13}^{\prime}=0.025 \mathrm{~m} \mathrm{~s}^{-2}, g_{23}^{\prime}=0.008$ $\mathrm{m} \mathrm{s}^{-2}, H_{1}=240 \mathrm{~m}$, and $H_{2}=345 \mathrm{~m}$. The corresponding first and second baroclinic mode gravity wave speeds are 2.67 and $1.23 \mathrm{~m} \mathrm{~s}^{-1}$. These values have been chosen such that the first-mode baroclinic Rossby waves in the model propagate at speeds similar to those inferred from XBT and satellite altimetry observations (e.g., Kessler 1990; van Woert and Price 1993; Chelton and Schlax 1996) and that the modeled layer-1 thickness matches the observed $26.0 \sigma_{\theta}$ surface. This is the densest iso- 
(a) Modeled mean upper layer thickness (m)

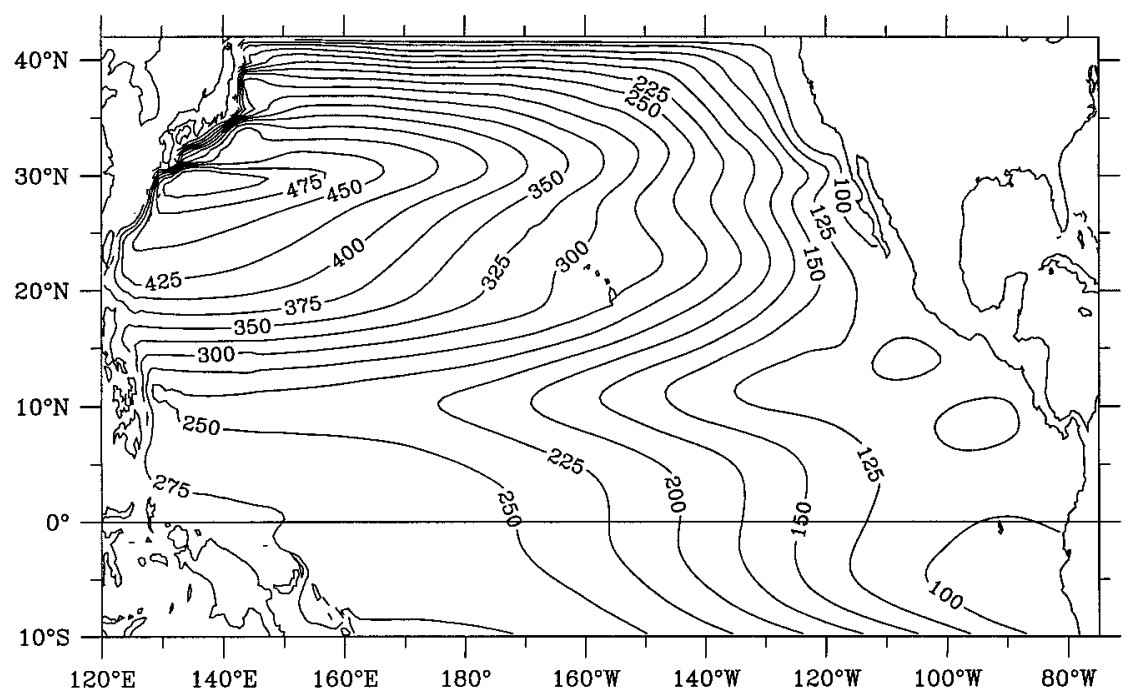

(b) Climatological upper layer thickness (m)

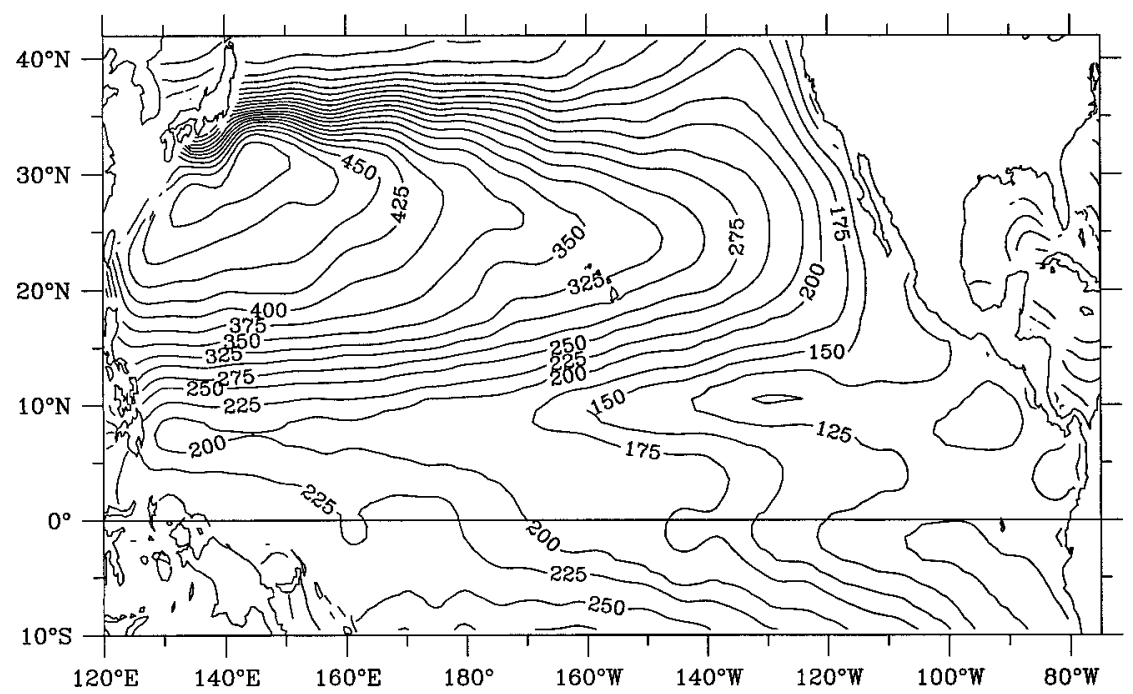

Fig. 9. (a) Mean upper-layer thickness field from the 30-yr model integration (1967-96). (b) Depth of the $26.0 \sigma_{\theta}$ surface based on the Levitus (1982) climatology.

pycnal that outcrops in the subtropical North Pacific (Huang and Qiu 1994).

The model ocean is first spun up by the monthly, climatological wind of Hellerman and Rosenstein (1983) for 20 years until a statistical steady state is reached. It is then forced by the monthly FSU wind (Goldenberg and O'Brien 1981) for the 36.5 years from January 1961 through July 1996. The pseudostress values of FSU were converted to surface wind stress by using a drag coefficient of $1.5 \times 10^{-3}$. In regions where monthly FSU wind data are not available (i.e., north of $30^{\circ} \mathrm{N}$ and west of $124^{\circ} \mathrm{E}$ ), we used the climatological monthly wind data instead; the TDIR calculation in the previous section indicates that winds north of $30^{\circ} \mathrm{N}$ have negligible effect on NHRC variability in any case. To avoid possible transient motions due to the switch from the climatological wind forcing to the FSU wind at the beginning of 1961, all our analyses are based on the model output after 1967.

\section{b. Mean circulation}

The $2 \frac{1}{2}$-layer reduced-gravity model adequately simulates the basin-scale, mean circulation pattern of the Pacific Ocean. Figure 9 compares the upper-layer thickness field from the 30-yr model integration (1967-96) to the Levitus (1982) climatology. To the east of the Hawaiian Islands, the modeled southwestward flow 
(a) mean flow field from model $\quad \longrightarrow 0.1 \mathrm{~m} / \mathrm{s}$

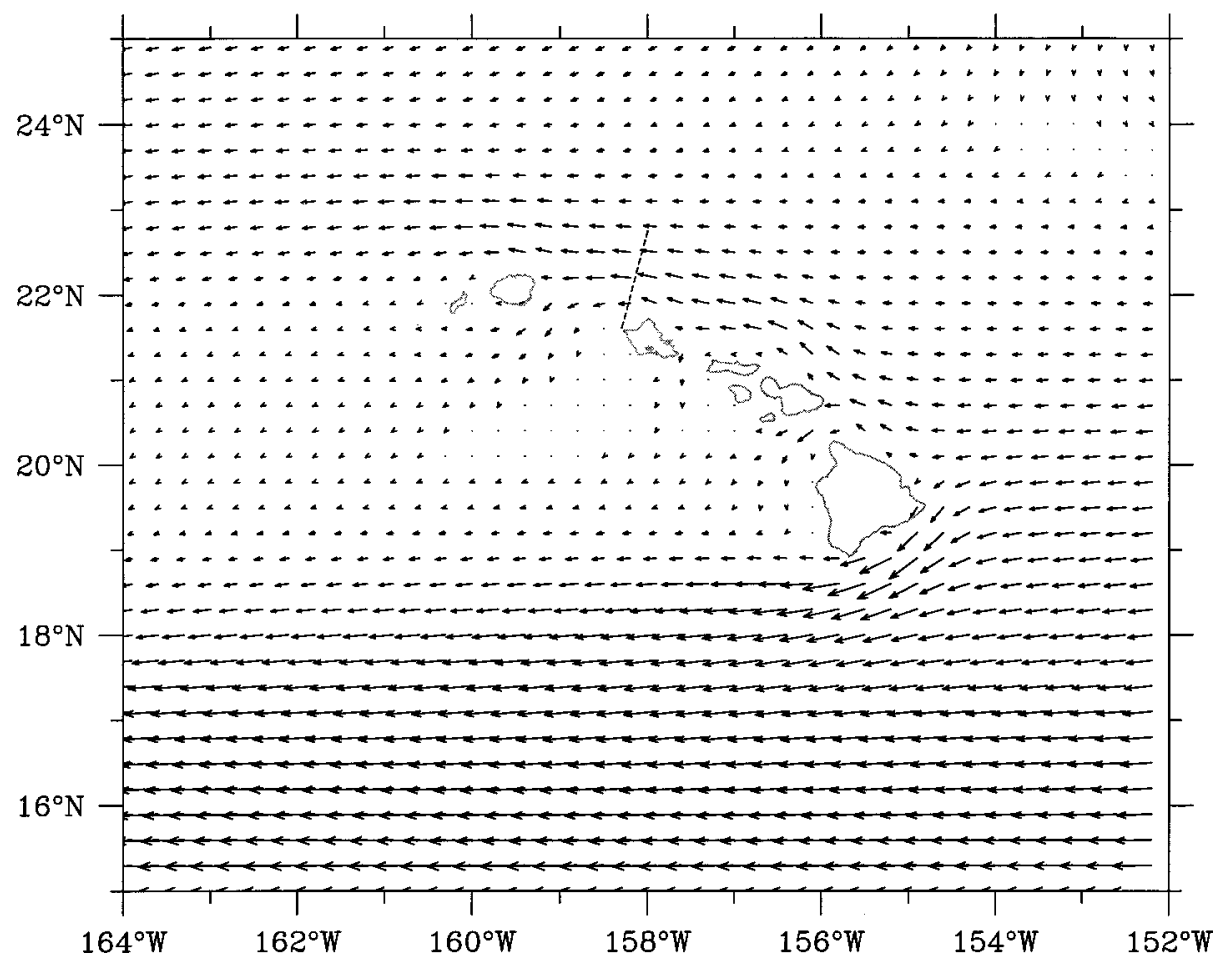

(b) mean flow field from drifter data $\rightarrow 0.2 \mathrm{~m} / \mathrm{s}$

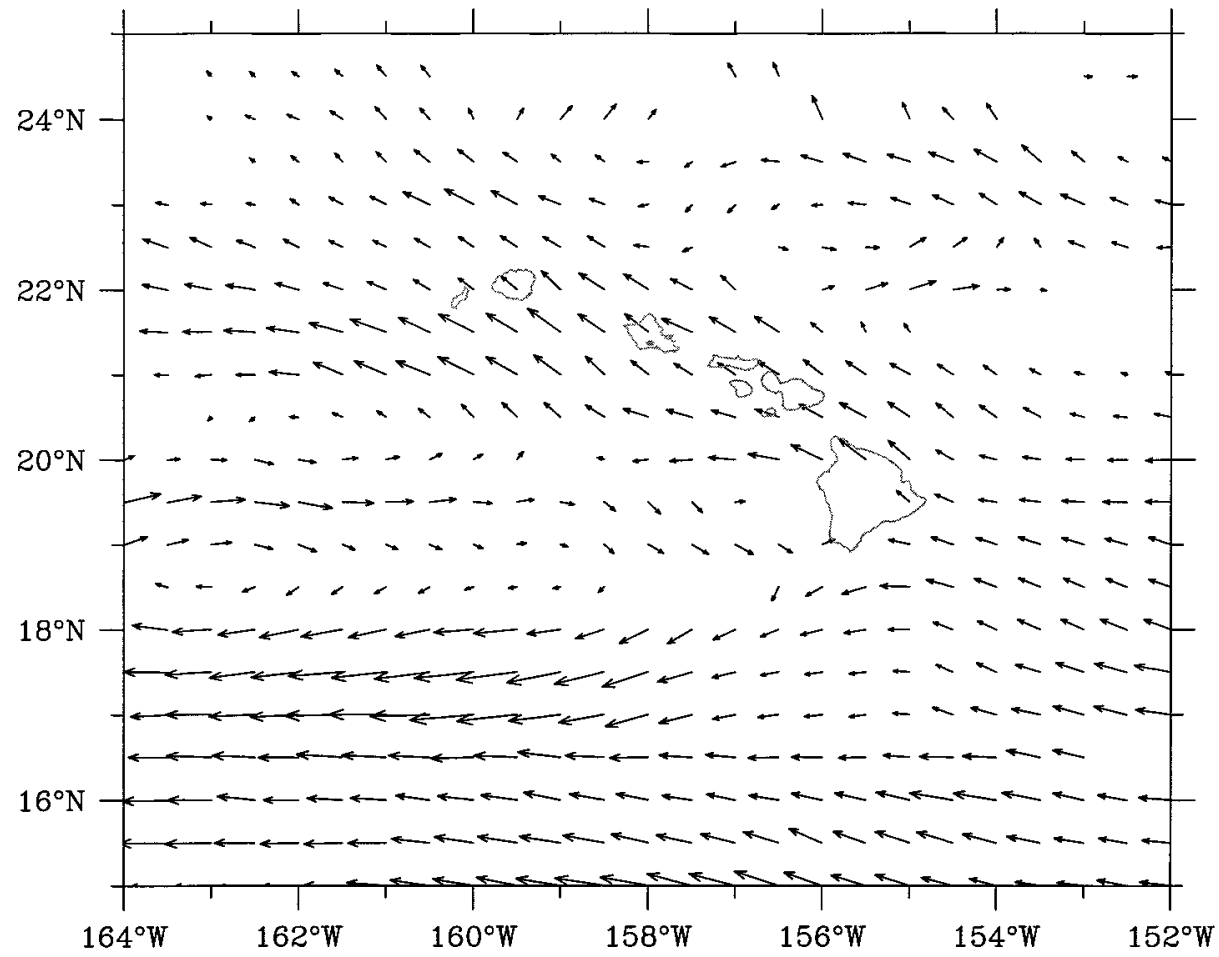

FIG. 10. (a) Surface layer flows averaged from the 30-yr model integration (1967-96). (b) Mean flow derived from long-term surface drifter data (adapted from Qiu et al. 1997a). 


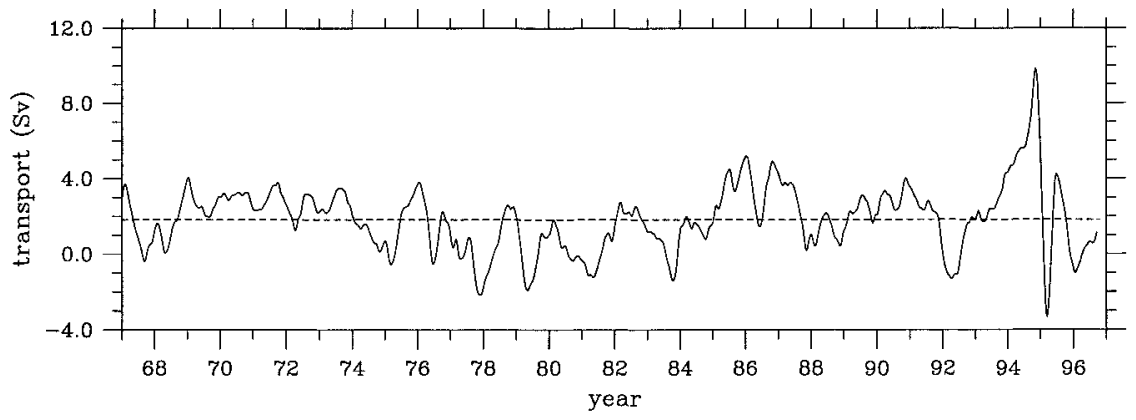

FIG. 11. Time series of the modeled NHRC transport (layers 1 and 2) across the ADCP transect. The dashed line shows the $30-\mathrm{yr}$ mean, $1.82 \mathrm{~Sv}$.

speed and direction are similar to the observed. The mean upper-layer currents near the Hawaiian Islands from the 30-yr model run is compared to the long-term drifter composite in Fig. 10. Both show a westward flow east of the Hawaiian Islands that splits at the island of Hawaii, with the southern branch joining the North Equatorial Current and the northern branch forming the NHRC. The modeled NHRC becomes a westward flow north of the island of Kauai, but this is unclear in the surface drifter data. Because of the paucity of drifters, a large zonal decorrelation scale, $3^{\circ}$, is used in mapping the mean flow, so features such as the NHRC in Fig. $10 \mathrm{~b}$ tend to be broadened, and even smeared across to the west of the Hawaiian Islands. Notice that the overall strength of the circulation in the model is about $20 \%-$ $30 \%$ weaker than in Fig. 10b. This is likely due at least in part to the difference in vertical sampling; the drifters are drogued at $15 \mathrm{~m}$, whereas Fig. 10a shows velocity averaged over the top 250-300 $\mathrm{m}$.

The model is less successful in simulating the circulation leeward of the Hawaiian Islands; the mean flow there is generally more quiescent in the model than in the surface drifter data, even after allowing for gridding artifacts in the latter. One possible cause for this is the lack of regional, through-channel wind shears in the monthly, $2^{\circ} \times 2^{\circ}$ FSU wind data. Such a sheared wind has been suggested by Patzert (1969) to play an important role in generating mesoscale eddies leeward of the Hawaiian Islands. As the focus of this study is on the NHRC, this problem associated with the leeward wind forcing is left to future studies.

The model NHRC transport time series is calculated as the integral over both active layers and along the actual ADCP section (Fig. 11). The mean transport over the 30-yr period (1967-96) is $1.82 \mathrm{~Sv}$, somewhat less than the $2.26 \mathrm{~Sv}$ averaged for the period from October 1988 through December 1996. During the latter period the ADCP transport from 10 to $170 \mathrm{~m}$ averaged $2.0 \mathrm{~Sv}$ (Fig. 3). This figure underestimates the NHRC as a whole; the integration is limited to the depth range sampled by the ADCP on all the cruises. The speed in the mean NHRC core drops by about a third as depth increases from 20 to $260 \mathrm{~m}$, below which the ADCP observations become too sparse for a reliable average.

\section{c. Variability}

A detailed comparison between the modeled transport of the NHRC and the ADCP observations is shown in Fig. 12. Although far from identical, the two time series share some common features. Both indicate that the NHRC transport was consistently positive prior to October 1991, but reversed during December 1991 to June 1992, and again briefly in early 1995. This latter event is particularly striking because it is atypical of the model time series. Much of the modeled variability near the annual period during 1989 through 1992 looks roughly like an attenuated version of the observed variability.

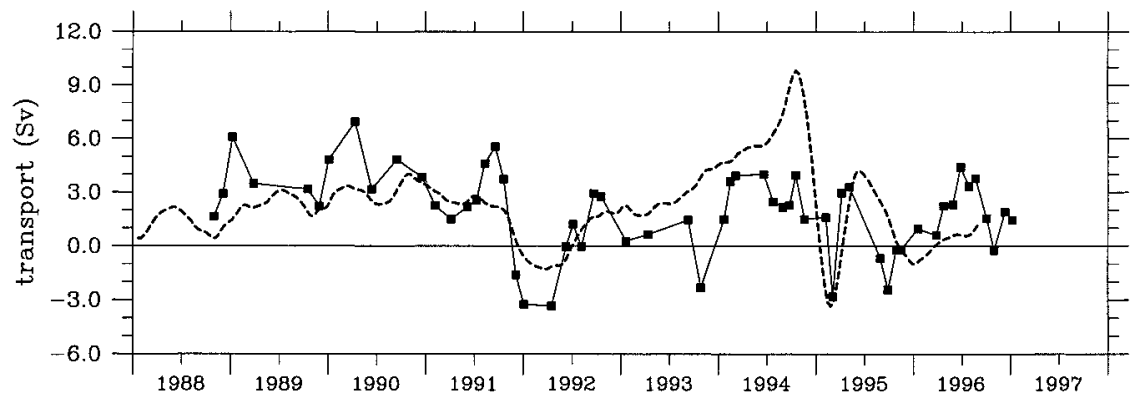

FIG. 12. Comparison between the modeled NHRC transport (dashed) and the ADCP estimates from Fig. 3 (solid squares). 


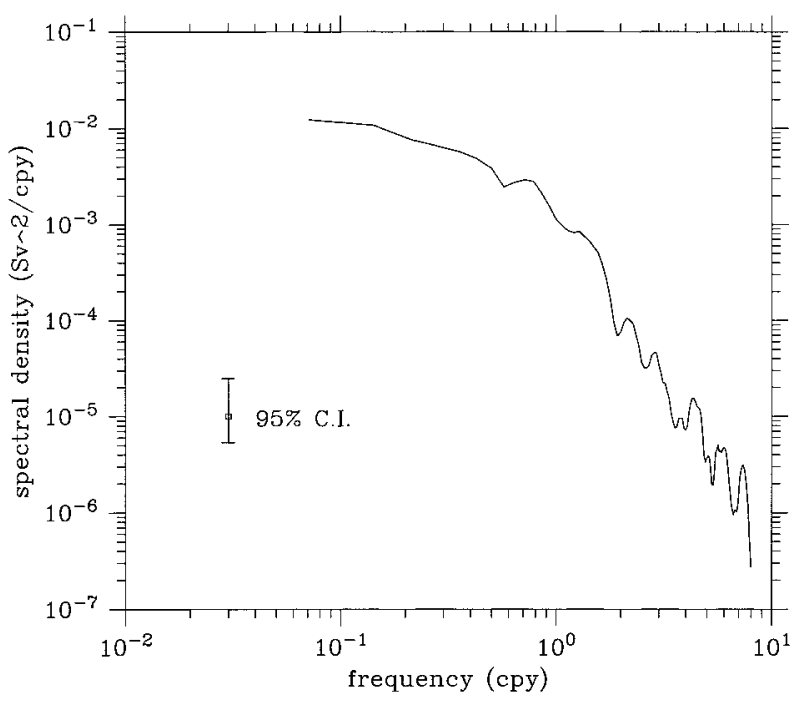

FIG. 13. Power spectrum of the modeled NHRC transport across the ADCP transect as shown in Fig. 11. The spectral estimate shown here is simply the average of the squared Fourier transforms of the first and second halves of the time series.

Discrepancies exist as well: the reversal of the NHRC observed in October 1993 was not simulated in the model, and the reversal observed in August to October 1995 occurred some 3 months later in the model-assuming they are indeed the same event. The strong model NHRC maximum in late 1994, prior to the sharp reversal in early 1995, has no counterpart in the observations. Overall, we believe the model contains much of the basic physics behind the real NHRC, but is still not up to the difficult task of hindcasting, forecasting, or simulating it in detail.

A striking feature of Fig. 11 is its variability on a broad range of timescales. The power spectral density of this time series is indeed red but otherwise surprisingly featureless (Fig. 13). We have noted the absence of a prominent annual cycle in the observed transport; similarly, there is no annual spectral peak in the modeled transport. In the low-frequency range also, there is no distinct peak in the $0.2-0.3$ cpy band, corresponding to the 3-5-yr period of the El Niño-Southern Oscillation (ENSO) phenomenon.

The TDIR derivation in the previous section included two types of forcing: 1) wind forcing around and to the east of the islands, but restricted to the latitude range of the islands ("local latitude wind forcing"), and 2) baroclinic Rossby waves radiating away from the eastern boundary, generated by coastal Kelvin waves (e.g., Enfield and Allen 1980; Chelton and Davis 1982), which may in turn have originated from equatorial winds and Kelvin waves ("remote latitude wind forcing"). Only the first of these was used in the TDIR calculations shown here, but the model includes both. To estimate the effect of equatorial winds on the modeled NHRC, we conducted a companion experiment forced by the monthly FSU winds poleward of $10^{\circ}$ and by the $1961-$
95 average $\mathrm{FSU}$ winds in the equatorial band $\left(10^{\circ} \mathrm{S}-\right.$ $\left.10^{\circ} \mathrm{N}\right)$. The NHRC transport time series from this experiment is nearly identical to that from the base model (Fig. 14a). The largest difference is during the energetic intraannual event in late 1994 and 1995. The distribution of equatorially forced energy is indicated by the rms difference in the upper-layer thickness between the base model case and the companion model case, normalized by the regional mean upper-layer thickness (Fig. 14b). The large ratios along the North American coast are due to the absence of the "equatorial origin" coastal Kelvin waves in the companion model. The influence of these coastal Kelvin waves propagates westward via baroclinic Rossby waves and diminishes gradually as the waves dissipate (Qiu et al. 1997b). Overall, Fig. 14 suggests that the variability of the NHRC is largely determined by the extra-equatorial wind in the North Pacific; the role of coastal Kelvin waves in the model is minor. The model underestimates coastal sea level variability by a factor of 2 to 3 (not shown), so the effect of equatorial forcing would be proportionally larger in reality than in the model, but it is still small compared to the local latitude wind forcing.

As the long-term ADCP measurements are limited to a section north of Oahu, it is interesting to use the model to infer how well that section represents neighboring waters. To do so, we compute the temporal cross-correlation coefficients between the modeled NHRC transport (Fig. 11) and the transport per unit width at nearby locations, projected in the direction of the local mean flow (Fig. 10a). As shown in Fig. 15, the correlation falls rapidly upstream; east of Maui, about $200 \mathrm{~km}$ southeast of the ADCP section, for example, the crosscorrelation coefficient drops below 0.4. This is consistent with the $\left(y-y_{s}\right)$ weighting in the second (and dominant) term in Eq. (17), as is the generally zonal orientation of the high correlation region. Flow through the channels between the islands, in phase with the NHRC, is also suggested by Fig. 15 and confirmed by time series plots of the through-channel flows (not shown).

Another question that can be addressed via the model is the importance of nonlinearity. As a simple test, a model run was made identical to the base case in every way except one: the wind stress was decomposed into a temporal mean field and a fluctuating component, and the latter was reduced in amplitude by a factor of 10 . The fluctuating component of the resulting NHRC time series was then multiplied by 10 before plotting. This procedure maintains the mean layer thickness topography, and hence the spatially variable Rossby wave speeds and refraction, while suppressing the advective terms in the momentum equation and the time-dependent layer thickness gradient terms in the continuity equation. The NHRC time series from the two cases are quite different (Fig. 16). The amplitude and time scales of the variability are similar, but many features do not match. The linear run, like the TDIR calculation shown 
(a) Modeled NHRC with/without interannual tropical wind

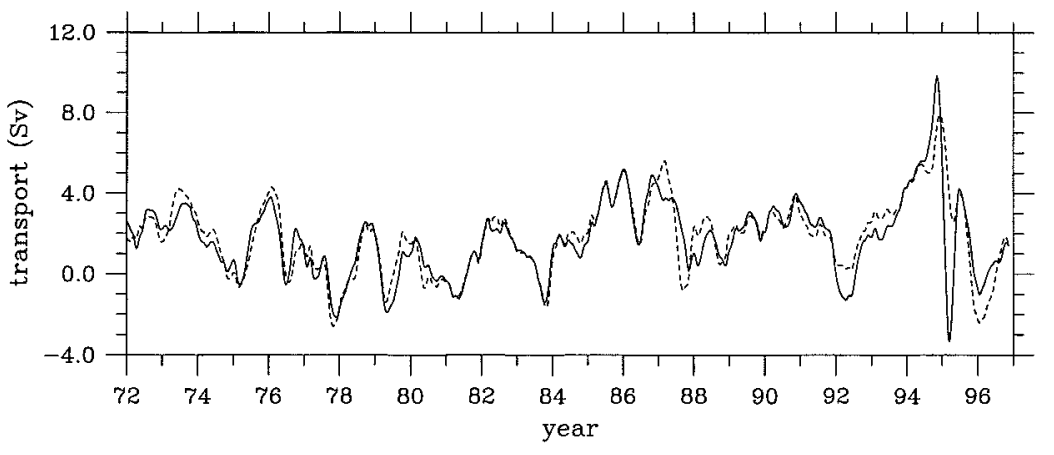

(b) Normalized rms difference in $h_{1}$ between the two model cases

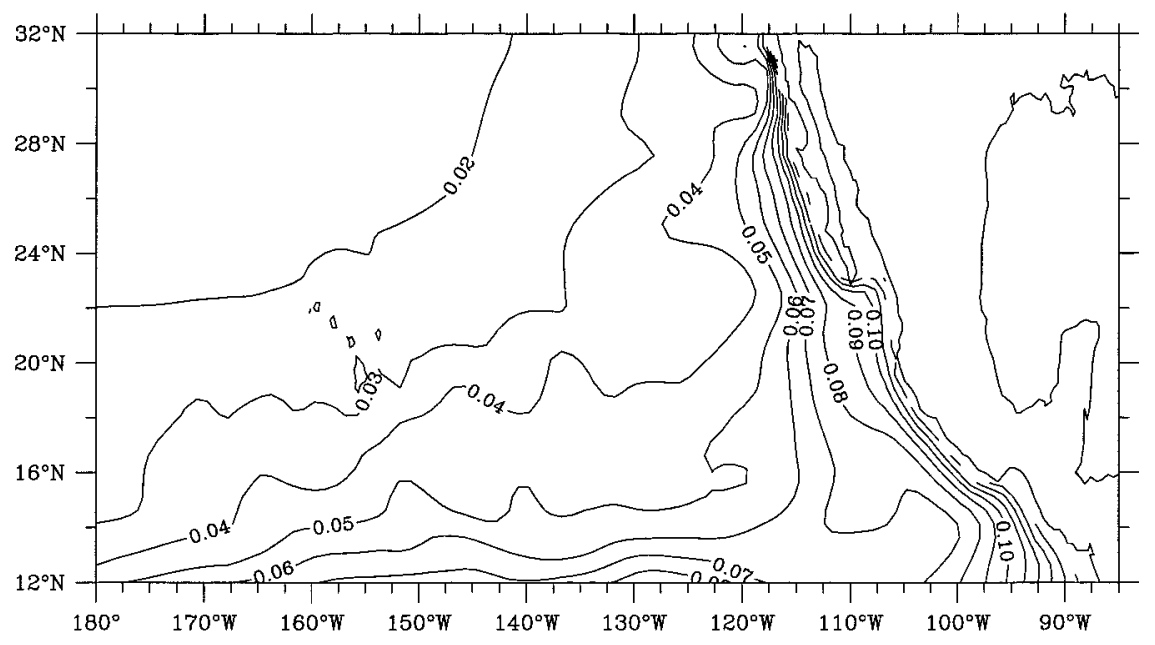

FIG. 14. (a) NHRC transport from the base model case (solid line; full wind forcing) and the companion experiment (dashed line; monthly FSU winds replaced by climatological mean in the $10^{\circ} \mathrm{S}-10^{\circ} \mathrm{N}$ equatorial band). (b) Rms difference in upper-layer thickness between the base and companion cases, as a fraction of the mean thickness from the base case.

in Fig. 5, appears to have more energy than the nonlinear at periods near $1.3 \mathrm{yr}$, while the nonlinear run looks more energetic at periods shorter than a year. The main conclusion is simply that nonlinearity is an important factor in NHRC variability.

To get a picture of the spatial scales of the interior variability that impinges on the NHRC, we look at maps of first baroclinic mode amplitude, based on the projection of the model layer thicknesses onto the linear vertical normal modes. The period chosen here is the $1.5 \mathrm{yr}$ from spring 1994 through summer 1995 (Fig. 17). This includes a very brief but pronounced reversal of the NHRC in both the ADCP sections and the model (Fig. 12). The maps show the fluctuation horizontal scales to be of order $1000 \mathrm{~km}$ in the interior, but intense eddies with smaller scales are sometimes generated near the islands. As an example, note the low pressure cell moving west along about $17^{\circ} \mathrm{N}$ in Figs. $17 \mathrm{a}-\mathrm{c}$ and the associated region of generally northwestward flow to the north of the eddy. It is the intensification of this northwestward flow along the windward side of the islands that causes the late-1994 peak in modeled NHRC. In Fig. 17c, an " $\mathrm{S}$ " has developed in the northwestward flow, which intensifies and then breaks up into smaller eddies. The reversal of the NHRC in early 1995 is associated with one such small eddy. The wind field deviations from the annual mean during this period (not shown) do not show such small-scale and intense features around the islands, so the current features must be caused by a combination of short Rossby wave reflection and nonlinearity.

\section{Discussion}

Several factors contribute to the differences among the NHRC estimates from the model, the island rule, and the ADCP observations. We have noted the sensitivity of the calculations to the wind product; this sensitivity would be reduced if the island had a larger meridional extent so that the TDIR would respond to larger 


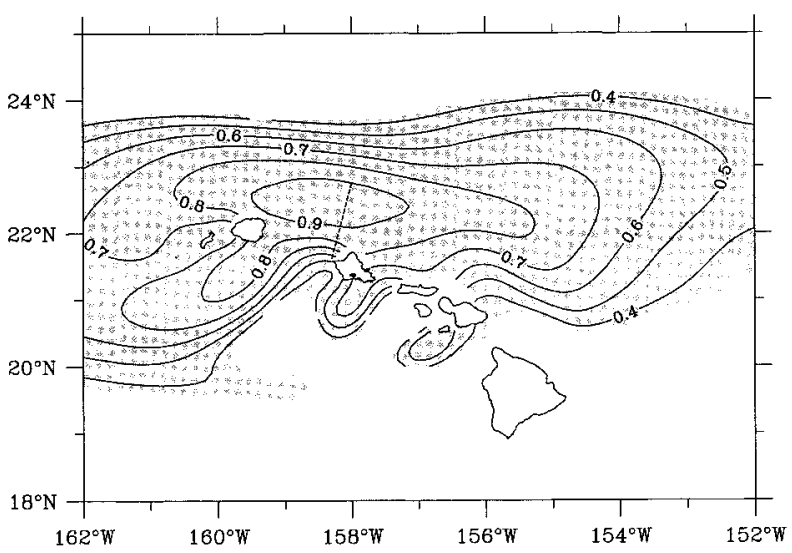

FIG. 15. Pointwise cross-correlation coefficient between the modeled NHRC transport (Fig. 11) and the transport per unit width projected in the direction of the local mean flow. Coefficients are plotted only in the area centered north of Oahu and only if they differ from zero at the $99 \%$ confidence level $(r=0.33)$.

scales in the wind field. We have also shown that nonlinearity makes a big difference in the model prediction, indicating probable sensitivity to details of the model formulation and forcing. The TDIR calculation is additionally handicapped by lack of Rossby wave dissipation; Fig. 14b implies that Rossby waves generated by wind forcing far to the east of the islands, in addition to those generated by coastal Kelvin waves, will have relatively little influence on the NHRC. Dissipation could be added to the TDIR, but given its other limitations this would have little practical benefit.

Nevertheless, the model and the island rule remain useful tools for understanding NHRC dynamics. The island rule in particular provides a lowest-order theoretical framework for understanding the low-frequency variability of the NHRC, though not for predicting it in detail.

The upper-layer TDIR has been derived in a way that emphasizes a key point: the idealized NHRC is just a quasi-steady baroclinic western boundary current that passively accepts inflows and outflows from the interior ocean east of the island. It distributes the flow between the northern and southern ends of the island in accordance with an overall vorticity constraint that includes a circumisland wind term. This is most clearly seen in (17). Consider first the effect of circumisland winds, the first rhs term in (17). Suppose the island is just a meridional line segment, and suppose that on average the difference in meridional wind stress between the east side of the island and the offshore side of the NHRC is $\Delta \tau_{w}^{y}$. Then the NHRC transport caused by this wind is just $\Delta \tau_{w}^{y} /(\beta \rho)$, independent of the length of the island. For example, $\Delta \tau_{w}^{y}=0.02 \mathrm{~Pa}$ generates $1 \mathrm{~Sv}$ of transport.

Next, consider the second rhs term in (17), which gives the contribution to NHRC transport of inflows from the interior. It can be split into two parts: Ekman transport and upper-layer geostrophic transport. Suppose there is a uniform longshore wind stress $\tau_{w}^{l}$ on the offshore edge of the NHRC. Half of the resulting Ekman transport will then have to be carried by the NHRC, with the other half going around the south end of the island. If the length of the island chain is $L$, the NHRC transport contribution is $\left(\tau_{w}^{l} L\right) /(2 f \rho)$. For the Hawaiian Islands, $L \approx 400 \mathrm{~km}$, so $\tau_{w}^{l}=0.05 \mathrm{~Pa}$ would contribute only $0.2 \mathrm{~Sv}$ to the NHRC. Hence, the direct Ekman transport contribution to the mean NHRC and its variability is small.

The upper-layer geostrophic transport through the offshore edge of the NHRC is the primary determinant of both the mean NHRC transport and its low-frequency variability. In the low-frequency limit, this inflow is determined by the Sverdrup balance; the NHRC transport is the difference between the meridionally averaged Sverdrup transport and the local Sverdrup transport at $y_{n}$. Hence, it is inherently much smaller than the interior Sverdrup transport at any given latitude. If the Sverdrup transport were constant over the latitude span of the island, the NHRC transport would be identically zero (apart from local wind effects discussed above). In the case of the Hawaiian Islands, the Sverdrup transport due to the mean winds east of the islands is approximately $10 \mathrm{~Sv}$, but the mean NHRC transport is $2 \mathrm{~Sv}$.

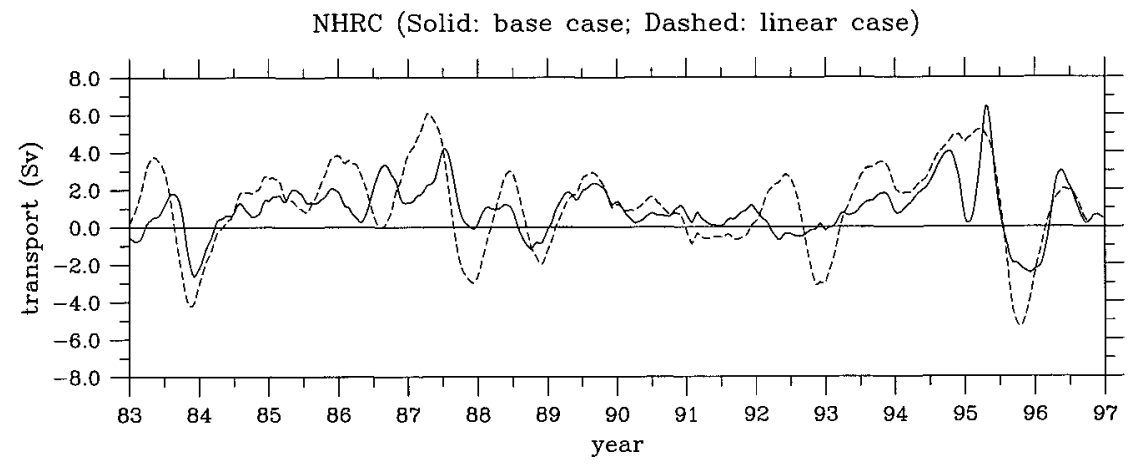

FIG. 16. Transport time series from the base case run (solid line) and from a linearized run (dashed), across a line segment at $21.75^{\circ} \mathrm{N}$ extending $2.6^{\circ}$ in longitude east of the Hawaiian Ridge. 
(a) $1994 / \mathrm{AMJ}$

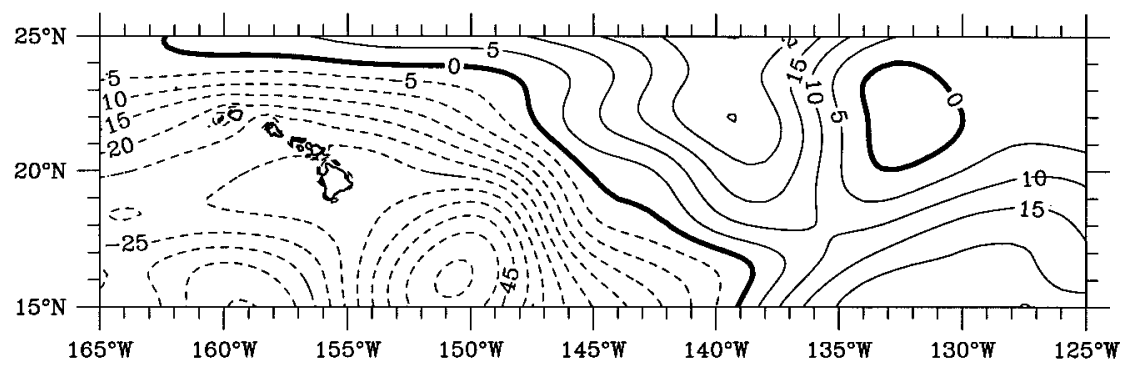

(b) $1994 / \mathrm{JAS}$

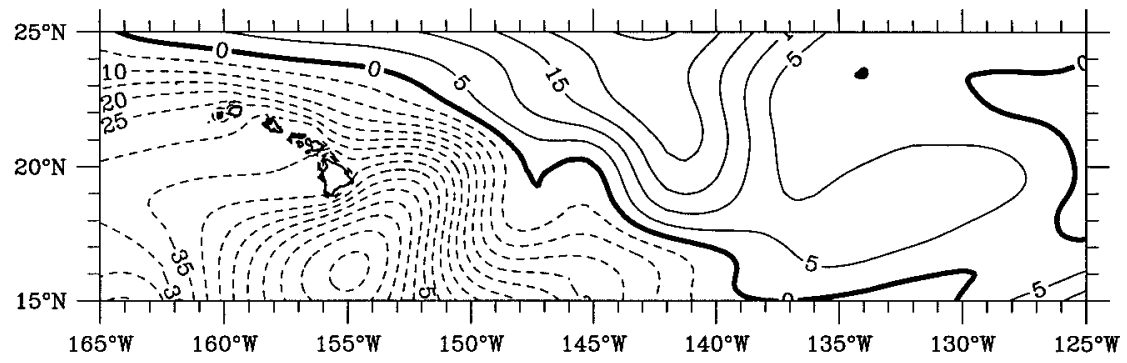

(c) $1994 / \mathrm{OND}$

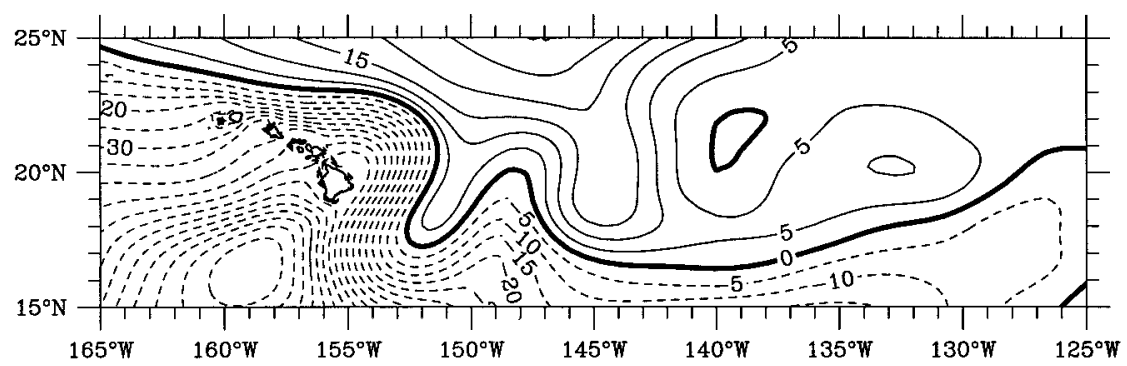

FIG. 17. Seasonally averaged first baroclinic mode amplitudes from the base model. The first mode amplitude in this $2 \frac{1}{2}$-layer system is $h_{1}+0.426 h_{2}$, where $h_{i}$ is the layer thickness anomaly in meters of layer $i$.

For forcing at frequencies $\omega \gg c_{r} /\left(x_{e}-x_{w}\right)$, baroclinic Rossby waves are not fast enough to establish a Sverdrup balance in the upper layer. In the case of Hawaii, approximating the distance to the eastern boundary as $5000 \mathrm{~km}$ and the Rossby radius of deformation as $60 \mathrm{~km}$, this corresponds to periods less than $20 \mathrm{yr}$ and therefore applies to most of the variability in Fig. 5. The baroclinic geostrophic inflow to the NHRC can then be viewed as the sum of a direct response to Ekman pumping plus a Rossby wave component of similar magnitude, or smaller if it is largely damped in transit (Qiu et al. 1997b). The order of magnitude of the total can be estimated from the Ekman pumping contribution alone, that is from (7) without the second term on the lhs. The upper-layer thickness anomaly is then the time integral of the Ekman pumping, so the amplitude of upper-layer thickness response increases linearly with the period of the forcing; the spectrum of the response is redder than the spectrum of the wind forcing by a factor of $\omega^{-2}$. At the annual frequency, for example, the wind stress curl amplitude east of Hawaii is about $3 \times$ $10^{-8} \mathrm{~N} \mathrm{~m}^{-3}$, calculated from Hellerman and Rosenstein (1983). The amplitude of the upper-layer thickness annual cycle due to Ekman pumping is therefore only about $3 \mathrm{~m}$-hence the negligible annual cycle in the NHRC.

In addition to the direct Ekman inflow and the baroclinic geostrophic inflow, there is a barotropic geostrophic inflow. For scales of $500 \mathrm{~km}$ and larger, the barotropic Rossby wave phase speed exceeds $5 \mathrm{~m} \mathrm{~s}^{-1}$, so at periods greater than two months the barotropic mode reflects the Sverdrup balance. The magnitude of transport variability at annual and lower frequencies is the same order as, or smaller than, the mean Sverdrup transport; but the contribution to the upper-layer NHRC is reduced by the ratio of the upper-layer thickness to 
(d) $1995 /$ JFM

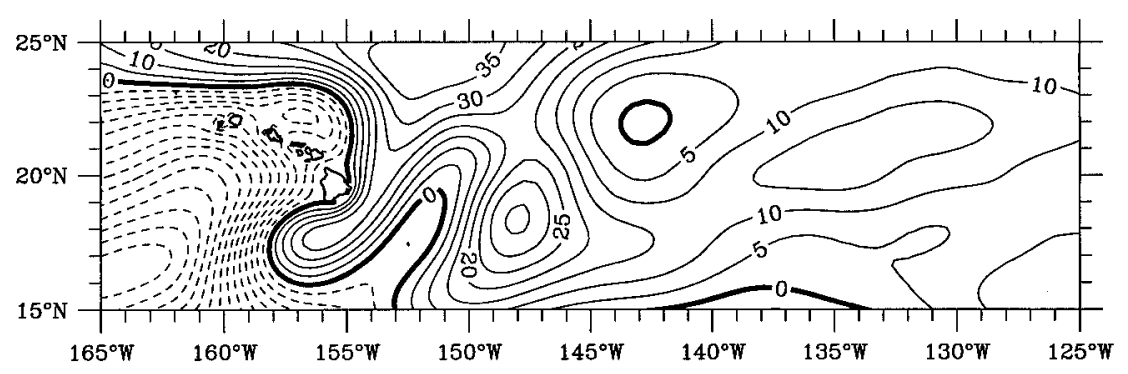

(e) $1995 / \mathrm{AMJ}$

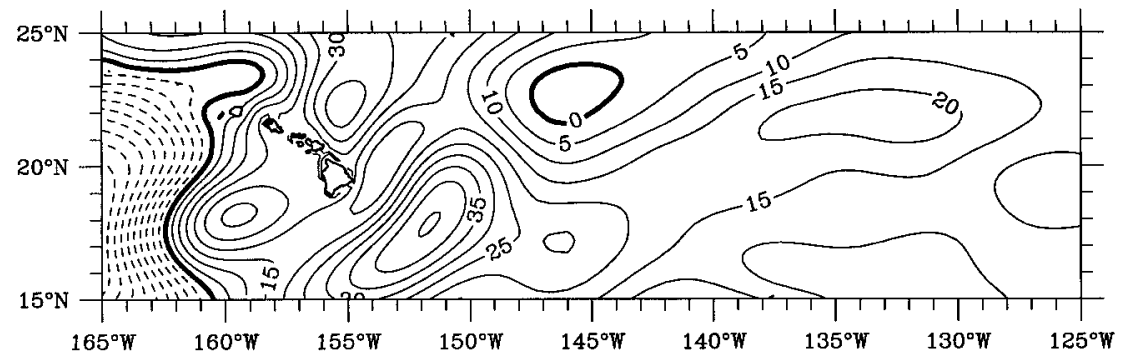

(f) $1995 / \mathrm{JAS}$

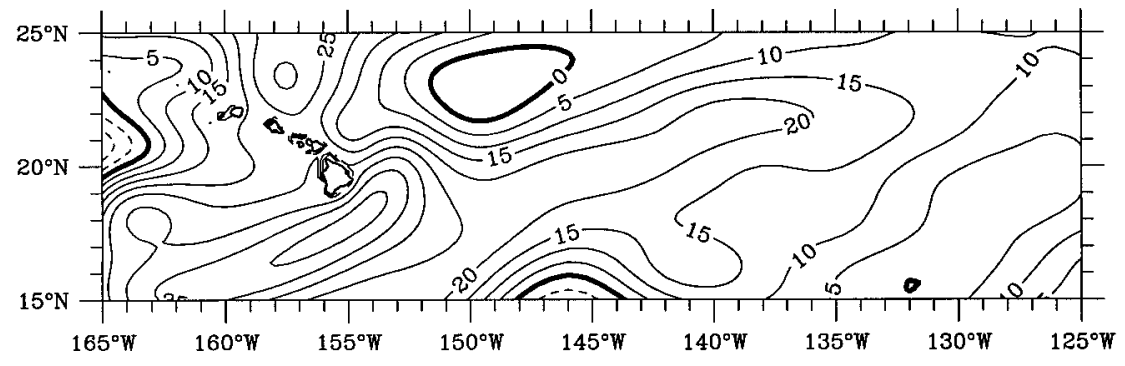

FIG. 17. (Continued)

the total thickness, about $10 \%$, and is therefore of order $0.2 \mathrm{~Sv}$ or less.

The insensitivity of the NHRC to equatorial winds (Fig. 14) results from two factors: At annual and higher frequencies, dissipation effectively damps Rossby waves radiated from the eastern boundary. At lower frequencies dissipation is less effective, but the Rossby waves are longer; the current associated with a given sea level perturbation varies inversely with the wavelength, and so does the resulting inflow to the NHRC. Variability of the NHRC is driven by changes in sea level slope, hence geostrophic current, not by changes in sea level itself.

\section{Summary}

The NHRC transport as measured by a shipboard ADCP section time series varies by several times its long-term mean and sometimes reverses. A simple linear theory for the variability at annual and interannual pe- riods, the TDIR, roughly reproduces the magnitude of the observed transport variations and features such as the absence of a regular annual cycle, but it does not match the observations in detail. A numerical model adds dynamical processes such as dissipation and nonlinearity that are absent from the TDIR. Agreement with the observations looks slightly better by eye, but is still not good; the numerical model is not yet up to the task of accurately predicting the NHRC transport. Nevertheless, the TDIR and the model provide insight into the dynamics of NHRC variability and into the difficulty of making accurate predictions. The analysis suggests that the TDIR and simple numerical models may have much better predictive value in other locations; the NHRC is probably a "worst case" because of its small meridional extent.

Acknowledgments. This study was supported by NSF through Grant OCE94-03048 and by NOAA through Cooperative Agreement NA37RJ0199. The ADCP mea- 
surements were supported by NSF through Grant OCE93-03094 as part of the Hawaii Ocean Time-series (HOT) program. Comments by the reviewers led to substantial improvements in the manuscript. We are grateful to the Center for Ocean-Atmospheric Prediction Studies (COAPS) at The Florida State University for providing the surface wind data and to the Maui High Performance Computer Center for the computer time used in our modeling work.

\section{REFERENCES}

Bingham, F. M., 1998: Evidence for the existence of a North Hawaiian Ridge Current. J. Phys. Oceanogr., 28, 991-998.

Chelton, D. B., and R. E. Davis, 1982: Monthly mean sea level variability along the west coast of North America. J. Phys. Oceanogr., 12, 757-784.

— and M. G. Schlax, 1996: Global observations of oceanic Rossby waves. Science, 272, 234-238.

Enfield, D. B., and J. S. Allen, 1980: On the structure and dynamics of monthly mean sea level anomalies along the Pacific coast of North and South America. J. Phys. Oceanogr., 10, 557-578.

Firing, E., 1996: Currents observed north of Oahu during the first five years of HOT. Deep-Sea Res., 43, 281-303.

Gill, A. E., 1982: Atmosphere-Ocean Dynamics. Academic Press, $662 \mathrm{pp}$.

Godfrey, J. S., 1989: A Sverdrup model of the depth-integrated flow for the world ocean allowing for island circulations. Geophys. Astrophys. Fluid Dyn., 45, 89-112.

Goldenberg, S. R., and J. J. O'Brien, 1981: Time and space variability of tropical Pacific wind stress. Mon. Wea. Rev., 109, 1190-1207.

Hellerman, S., and M. Rosenstein, 1983: Normal monthly wind stress over the world ocean with error estimates. J. Phys. Oceanogr., 13, 1093-1104.

Huang, R. X., and B. Qiu, 1994: Three-dimensional structure of the wind-driven circulation in the subtropical North Pacific. J. Phys. Oceanogr., 24, 1608-1622.

Kalnay, E., and Coauthors, 1996: The NCEP/NCAR 40-Year Reanalysis Project. Bull. Amer. Meteor. Soc., 77, 437-471.

Kessler, W. S., 1990: Observations of long Rossby waves in the northern tropical Pacific. J. Geophys. Res., 95, 5183-5217.
Levitus, S., 1982: Climatological Atlas of the World Ocean. NOAA Prof. Paper No. 13, U.S. Govt. Printing Office, Washington, DC, $173 \mathrm{pp}$.

McCreary, J. P., and P. Lu, 1994: On the interaction between the subtropical and the equatorial oceans: The subtropical cell. $J$. Phys. Oceanogr., 24, 466-497.

Mysak, L. A., and L. Magaard, 1983: Rossby wave driven Eulerian mean flows along non-zonal barriers, with application to the Hawaiian Ridge. J. Phys. Oceanogr., 13, 1716-1725.

O'Brien, J. J., and H. E. Hurlburt, 1972: A numerical model of coastal upwelling. J. Phys. Oceanogr., 2, 14-26.

Patzert, W. C., 1969: Eddies in Hawaiian waters. HIG 69-8, Hawaii Institute of Geophysics, Honolulu, HI, 51 pp.

Pedlosky, J., L. J. Pratt, M. A. Spall, and K. R. Helfrich, 1997: Circulation around islands and ridges. J. Mar. Res., 55, 11991251.

Price, J. M., M. L. van Woert, and M. Vitousek, 1994: On the possibility of a ridge current along the Hawaiian Islands. J. Geophys. Res., 99, 14 101-14 111.

Qiu, B., D. Koh, C. Lumpkin, and P. Flament, 1997a: Existence and formation mechanism of the North Hawaiian Ridge Current. $J$. Phys. Oceanogr., 27, 431-444.

- W. Miao, and P. Muller, 1997b: Propagation and decay of forced and free baroclinic Rossby waves in off-equatorial oceans. $J$. Phys. Oceanogr., 27, 2405-2417.

van Woert, M. L., and J. M. Price, 1993: Geosat and Advanced Very High Resolution Radiometer observations of oceanic planetary waves adjacent to the Hawaiian Islands. J. Geophys. Res., 98, 14 619-14 631.

Wajsowicz, R. C., 1993: The circulation of the depth-integrated flow around an island with application to the Indonesian Throughflow. J. Phys. Oceanogr., 23, 1470-1484.

_ - 1994: A relationship between interannual variations in the South Pacific wind stress curl, the Indonesian Throughflow, and the west Pacific warm water pool. J. Phys. Oceanogr., 24, 2180 2187.

- 1995: The response of the Indo-Pacific throughflow to interannual variations in the Pacific wind stress. Part I: Idealized geometry and variations. J. Phys. Oceanogr., 25, 1805-1826.

White, W., 1983: A narrow boundary current along the eastern side of the Hawaiian Ridge: The north Hawaiian Ridge current. $J$. Phys. Oceanogr., 13, 1726-1731.

Wyrtki, K., and G. Meyers, 1976: The trade wind field over the Pacific Ocean. J. Appl. Meteor., 15, 698-704. 